\title{
Clasificación energética de edificios. Efectos del cambio en la normativa y los métodos constructivos en la zona climática española A4
}

\author{
Victor FERNÁNDEZ MEMBRIVE \\ Departamento de Ingeniería \\ Universidad de Almería \\ vfernandezmat@gmail.com \\ Xavier LASTRA BRAVO \\ Departamento de Ingeniería \\ Universidad de Almería \\ xlastra@ual.es \\ Isabel FLORES PARRA \\ Departamento de Ingeniería \\ Universidad de Almería \\ iflores@ual.es
}

Recibido: 13 de septiembre de 2013

Enviado a evaluar: 17 de septiembre de 2013

Aceptado: 3 de octubre de 2013

\section{RESUMEN}

España tiene una de las tasas más altas de consumo energético respecto del PIB en la Unión Europea, siendo la edificación uno de los principales sectores demandantes de energía. Normativas como el Real Decreto 235/2013 o el Código Técnico de la Edificación, incorporan avances significativos en la eficiencia energética de los edificios, cambiando los métodos de construcción y en especial, haciéndolos más eficientes. El propósito de este estudio es analizar los efectos de los cambios introducidos por dicha normativa en los métodos de construcción en Almería (Zona Climática Española A4) en tres períodos diferentes (1988-1994, 1995-2006 y 2007 hasta la fecha). Uno de los principales resultados observados es que los cambios en los métodos de construcción disminuyeron el consumo de energía primaria y las emisiones totales de $\mathrm{CO}_{2}$ en aproximadamente un $50 \%$. Esta reducción, está de acuerdo con la actual política energética europea, que pretende mejorar la eficiencia energética en un $20 \%$ hasta 2020.

Palabras clave: Métodos constructivos, zona climática española A4, Código Técnico de la Edifícación, Unión Europea, Política Energética Europea.

\section{Building energy rating. Effects of changing regulations and construction methods in the Spanish climate A4}

\begin{abstract}
Spain has one of the highest energy consumption rates per GDP in the European Union, and the construction industry is one of its main energy demands. Royal Decree 235/2013 or the Technical Building


Code, partially transposed from the European Directive on Energy Performance of Buildings, has changed construction methods in an attempt at improving energy efficiency in buildings. The purpose of this study is to analyze the effects of changes in construction methods in Almeria (Spanish Climate Zone A4) in three different periods (1988-1994, 1995-2006 and 2007 to date). One of the main results was that it was observed that changes in the construction methods decreased primary energy consumption and overall $\mathrm{CO}_{2}$ emissions by about $50 \%$, which is in agreement with the current European energy policy, which intends to improve energy efficiency by $20 \%$ by 2020 .

Key words: Constructive methods, Spanish climate zone A4, Technical Building Code, European Union, European Energy Policy.

\section{Évaluation des bâtiments énergétique. Effets de l'évolution de la} réglementation et des méthodes de construction dans le climat espagnol A4

\section{RÉSUMÉ}

L'Espagne a l'un des taux les plus élevés de consommation d'énergie au PIB dans l'Union européenne, le bâtiment étant l'un des principaux utilisateurs d'énergie. Règlement et le décret royal 235/2013 ou le Code du bâtiment technique, constituée des avancées significatives dans l'efficacité énergétique des bâtiments, les méthodes de construction ont changé, les rendant plus efficaces. Le but de cette étude est d'analyser les effets des changements introduits par ces méthodes de construction de la législation à Almería (Climate Espagnol Zone A4) dans trois périodes différentes (1988-1994, 1995-2006 et 2007 à ce jour). L'un des principaux résultats observés est que les changements dans les méthodes de construction ont diminué la consommation d'énergie primaire et les émissions de $\mathrm{CO} 2$ de $50 \%$, ce qui est d'accord avec la politique énergétique européenne actuelle, qui vise à améliorer l'efficacité énergétique de $20 \%$.

Mots-clés: Méthodes constructives, Espagnol zone A4 climatique, Code Technique de la Construction, de l'Union européenne, la politique européenne de l'énergie.

\section{INTRODUCCIÓN}

El equilibrio entre el desarrollo sostenible, la competitividad y la seguridad de abastecimiento es el objetivo de la actual política energética de la Unión Europea (UE) [1]. Para alcanzarlo, es necesaria la promoción de la eficiencia energética, el uso de las energías renovables y la publicación de directrices y documentos dirigidos al sector de la energía [2]. La Comisión Europea publicó la Comunicación COM(2007) 1 final, donde se propone una política energética para luchar contra el cambio climático y basada en una economía con un consumo reducido de energía, a través de una energía sostenible, segura y competitiva [4]. Sobre la base de la propuesta de la Comisión, el Consejo Europeo aprobó lo que se conoce como objetivos 20/20/20 $[3,5]$, que constituyen la base de la actual estrategia en política energética. Los objetivos 20/20/20 son de aplicación en la Unión Europea 27 (UE-27), formada por: Austria, Bélgica, Bulgaria, Chipre, la República Checa, Dinamarca, Estonia, Finlandia, Francia, Alemania, Grecia, Hungría, Irlanda, Italia, Letonia, Lituania, Luxemburgo, Malta, Países Bajos, Polonia, Portugal, Rumania, Eslovaquia, Eslovenia, España, Suecia y el Reino Unido. Los objetivos 20/20/20 son: Aumentar la eficiencia energética para alcanzar una meta de $20 \%$ de ahorro en el consumo energético de la UE, de 
acuerdo con el Libro Verde de la Comisión sobre la proyección de eficiencia energética para 2020:

- Reducir las emisiones de gases de efecto invernadero al menos en un $20 \%$ respecto a 1990 y 2020.

- Lograr una participación del $20 \%$ de energías renovables en el consumo total de energía de la UE en 2020.

- Incrementar el uso de biocombustibles en el transporte de al menos el $10 \%$ del total de combustible (gas-oil y gasolina) consumidos en la UE en 2020.

El fomento de la eficiencia energética es, posiblemente, la única política energética que contribuye a todos los objetivos energéticos básicos de la UE, ya que tiene una relación directa con la reducción de las emisiones de gases de efecto invernadero y la mitigación del cambio climático, la gestión de la seguridad energética, la reducción del precio de los servicios energéticos a los consumidores y la mejora de la competitividad económica [6,7]. Si se hace de una manera rentable, el cumplimiento de estos objetivos estratégicos contribuiría a [8]:

- Una mayor independencia de las importaciones de energía y el suministro seguro.

- El crecimiento económico y la creación de empleo.

- La reducción de las emisiones de gases de efecto invernadero y el impacto nocivo de la generación de energía en el ambiente.

- La mejora de las condiciones de vida y el bienestar para sus ciudadanos.

A través de los efectos combinados de la plena aplicación de las medidas existentes, y de otras nuevas, sería posible transformar nuestra vida cotidiana, tendría el potencial de generar un ahorro económico de hasta $1000 €$ por hogar cada año, mejorar la competitividad industrial de Europa, crear un máximo de 2 millones de empleos, y reducir las emisiones anuales de gases de efecto invernadero en 740 millones de toneladas [9].

Las áreas críticas que actualmente tienen el mayor potencial de ahorro energético son: la eficiencia energética de productos, edificios y servicios, la transformación de energía, el transporte, la financiación y el coste, el comportamiento energético y el desarrollo de asociaciones internacionales [10].

Dentro de Europa, España es uno de los países con mayor índice de consumo energético por Producto Interior Bruto (PIB). En las últimas décadas, España presentó una tendencia inversa con respecto a la UE-15, incrementándose la demanda energética en un 10\% entre 1990 y 2006 [11]. A partir de 2006 comenzó una reducción que se ha mantenido hasta la actualidad, pero que no indican mejoras sustanciales en eficiencia [12].

Considerando que el gran potencial de ahorro energético recae en el sector de la edificación, ya que casi el $40 \%$ del consumo final se da en uso residencial y terciario (oficinas, tiendas y otros edificios) [13], la Comisión Europea publicó una directiva sobre eficiencia energética de los edificios (EPBD) (2002/91/ EC) [10] modificada por 2010/31/UE [14], que entró en vigor en el 2010, y está siendo implementada en la legislación de los Estados miembros de diferentes maneras. 
España hizo una serie de mejoras en la legislación relacionada. Entre ellas, la transposición de la Directiva 2002/91/CE EPBD (Energy Performance of Buildings Directive), la aprobación del Código Técnico de la Edificación (CTE) [15], el Real Decreto sobre el Procedimiento básico para la certificación de eficiencia energética de edificios de nueva construcción (RD 47/2007), aprobado por el Consejo de Ministros el 19 de enero de 2007, y la modificación del Reglamento de Instalaciones Térmicas de los Edificios (RITE) publicado el Real Decreto 238/2013 de 5 de abril y el Real Decreto 235/2013, de 5 de abril, por el que se aprobó el procedimiento básico para la certificación de eficiencia energética de los edificios trasponiendo tardíamente la refundición de 2010 de la EPBD (Directiva 2010/31/UE). Las principales regulaciones europeas son la Directiva 2002/91/CE, Directiva 2010/31/UE, el Reglamento 244/2012, Directiva 2010/31/UE y Directiva 2012/27/UE del 25 de octubre de 2012, y la normativa española son RD 314/2006, RD 1027/2007, y RD 235/2013.

Toda la legislación anterior es importante para mejorar la eficiencia energética en el sector de la construcción. Más aún por los primitivos sistemas de construcción y el aumento, que en lo últimos 10 años han tenido las actividades de construcción que llegaron a representar un porcentaje del 9.4\% del PIB, por encima de la UE-15 (5.2\%) [11]. Esta acción es el resultado de la fuerte inversión en infraestructura, en primera y segunda residencia durante el boom inmobiliario español, que desplazó la demanda de energía a otros sectores en detrimento del sector terciario [11.16].

Los objetivos de este artículo son conocer la influencia, el desarrollo y los problemas de la normativa existente en materia de eficiencia energética a nivel nacional y estudiar la evolución, en parte producida por el cambio legislativo, de los métodos constructivos de un proyecto existente ubicado en la zona climática española A4 (localidades en la provincia de Almería con una cota menor de 200m). Para ello, se han estudiado las normativas a nivel europeo y nacional, analizando los problemas y oportunidades que nos ofrecen. Posteriormente se estudia la evolución de los métodos constructivos en tres distintos periodos (1988-1994, 1995-2006 y 2007 hasta la fecha), de acuerdo con los cambios producidos en sus calidades, y se calcula la demanda energética de una promoción existente, construida en el año 2001, y la demanda de energía del mismo proyecto residencial, con los métodos de construcción de 1990 y de 2012. En el cálculo se mantuvieron: las orientaciones, superficies, morfología y el sombreado de los inmuebles. El artículo se organiza de la siguiente forma: en la Sección 2 se muestra el consumo energético a nivel nacional y europeo; la Sección 3 estudia el estado actual de la regulación de la eficiencia energética en España. En la Sección 4 se estudia y analiza la evolución de los métodos constructivos, las calidades y sistemas en la zona en estudio (Almería). En la Sección 5 se describe la metodología empleada para el análisis del cambio de normativa y los métodos constructivos. La sección 6 presenta los resultados y discute los efectos a consecuencia de los cambios en los métodos de construcción en la zona climática española A4. En la Sección 7 se analizan las oportunidades y problemas de la eficiencia energética en España. Finalmente, en la sección 8 se presentan las principales conclusiones del estudio. 


\section{CONSUMO ENERGÉTICO EN EUROPA Y EN ESPAÑA}

Los acciones realizadas por los gobiernos no son suficientes para lograr el objetivo 20/20/20 [5]. La Comisión, a través de la comunicación COM (2008) 772 final [3] sobre alcanzar el objetivo del $20 \%$, afirma que las tendencias actuales de eficiencia energética en los Estados miembros están poniendo en peligro dicho objetivo, a pesar de las medidas adoptadas. Esto hace que sea necesario intensificar los esfuerzos para alcanzar al menos el objetivo de ahorro energético del $20 \%$.

En la Tabla 1 se pueden comparar los consumos por países en la UE en viviendas con respecto a cuatro grandes bloques: calefacción, Agua Caliente Sanitaria (ACS), iluminación y aparatos eléctricos [21].

Tabla 1. El consumo unitario por vivienda por usuarios finales (tep / vivienda) (2009) ${ }^{\mathrm{a}}$

\begin{tabular}{lccccc}
\hline & Total & Calefacción & ACS & Cocina & Iluminación y electrodomésticos \\
\hline Luxemburgo & 3.79 & & & & \\
Finlandia & 2.05 & 1.46 & 0.21 & 0.03 & 0.36 \\
Irlanda & 1.98 & 1.36 & 0.32 & 0.08 & 0.22 \\
Bélgica & 1.97 & 1.43 & 0.22 & 0.07 & 0.24 \\
Austria & 1.79 & 1.33 & 0.2 & 0.03 & 0.23 \\
Letonia & 1.74 & 1.3 & 0.19 & 0.1 & 0.15 \\
Dinamarca & 1.69 & 1.42 & & 0.03 & 0.25 \\
Alemania & 1.61 & 1.18 & 0.19 & 0.04 & 0.19 \\
Suecia & 1.61 & 1.09 & 0.17 & 0.03 & 0.32 \\
Estonia & 1.59 & 0.98 & 0.31 & 0.2 & 0.09 \\
Francia & 1.56 & 1.07 & 0.16 & 0.08 & 0.24 \\
R. Unido & 1.55 & 0.97 & 0.26 & 0.04 & 0.28 \\
Rep. Checa & 1.53 & 1.07 & 0.23 & 0.07 & 0.16 \\
Países Bajos & 1.49 & 1 & 0.21 & 0.04 & 0.24 \\
EU-27 & 1.48 & 1.01 & 0.18 & 0.06 & \\
Hungría & 1.46 & & & & 0.23 \\
Eslovenia & 1.46 & 0.91 & 0.25 & 0.06 & 0.26 \\
Polonia & 1.45 & 1.01 & & & 0.19 \\
Grecia & 1.36 & 0.93 & 0.09 & 0.09 & 0.19 \\
Eslovaquia & 1.33 & 0.9 & 0.24 & 0 & 0.11 \\
Italia & 1.16 & 0.81 & 0.1 & 0.07 & 0.3 \\
Rumania & 1.15 & 0.55 & 0.14 & 0.34 & 0.13 \\
Chipre & 1.08 & 0.39 & 0.21 & 0.18 & 0.13 \\
Lituania & 1.06 & 0.75 & 0.08 & 0.11 & \\
España & 0.92 & 0.41 & 0.25 & 0.06 & \\
Portugal & 0.83 & & & & \\
Bulgaria & 0.72 & 0.5 & 0.04 & 0.05 & \\
Malta & 0.63 & & & & \\
\hline
\end{tabular}

Fuente: ODYSEEE

La tendencia en los Estados miembros de la UE es positiva, en un rango de entre el $31.9 \%$ de Letonia y el 2.4\% en Eslovaquia entre 2000-2010 (Figura 1). España logró un aumento de la eficiencia energética del $1 ., 6 \%$, que es inferior a la media de la UE27 (15.3\%). 
El porcentaje del consumo de calefacción residencial disminuyó en el periodo 2000-2010 en más de un 10\% (Tabla 2), sólo superado por Letonia, Eslovenia, Suecia y Chipre. Esta reducción es casi el doble de la realizada por la UE. En 2005, el consumo final de energía en el sector de la construcción se elevó a 18123 ktep sobre un total nacional de $106940 \mathrm{ktep}$ [26]. Esta cifra representa el 17\% del consumo de energía final nacional, de los cuales 10793 ktep corresponden al sector residencial (10\% del consumo nacional de energía) y $7330 \mathrm{ktep}$ al sector terciario (7\%). Esto significa que desde 2000 hasta 2005 el consumo final de energía en este sector aumentó un $5 \%$.

Figura 1. (a) aumento de la eficiencia energética en los hogares (\%), (b) El consumo por vivienda a escala en el clima promedio de la UE (tep / viv).

a)

b)
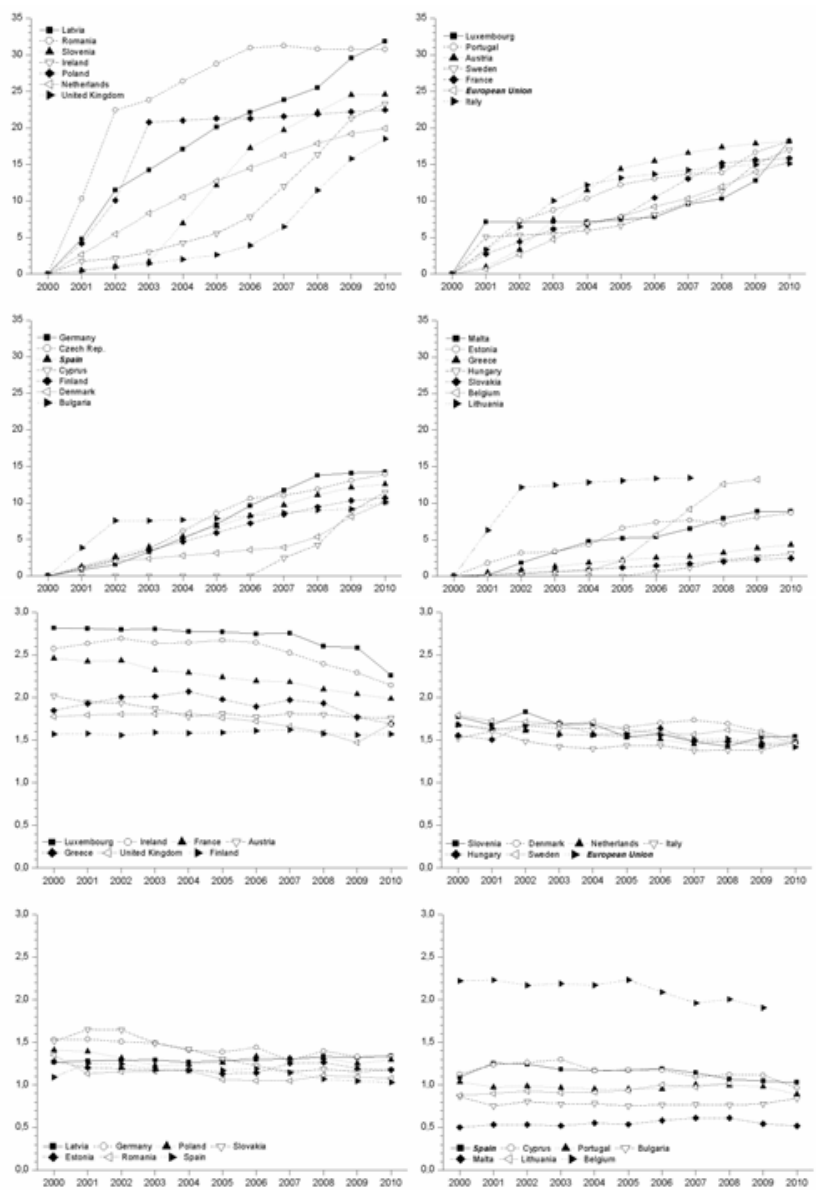

Fuente: Elaboración propia. 
En España, el consumo final de energía en el sector residencial se distribuye de media para uso residencial en calefacción $(41,7 \%)$, agua caliente sanitaria $(26,2 \%)$, iluminación $(9 \%)$ y aire acondicionado $(0,4 \%)$. El consumo restante se distribuye en electrodomésticos $(11,9 \%)$ y cocinas $(10,8 \%)$. Lógicamente, estos porcentajes varían de una zona climática a otra, el impacto de la calefacción de ser mucho menos en zonas cálidas que el aire acondicionado, y viceversa en zonas frías.

Tabla 2. El consumo final de calefacción para uso residencial con correcciones según el clima (Mtep) como porcentaje del consumo final residencial con las correcciones para el clima (Mtep)

\begin{tabular}{|c|c|c|c|c|c|c|}
\hline & 2000 & 2002 & 2004 & 2006 & 2008 & 2010 \\
\hline Dinamarca & 83.8 & 83.6 & 83.2 & 83.4 & 83.6 & 82.4 \\
\hline Alemania & 78 & 77.6 & 74.8 & 75.4 & 74.4 & 72.3 \\
\hline Bélgica & 76 & 75.8 & 76.3 & 75.4 & 74 & - \\
\hline Austria & 76.3 & 74.5 & 73.3 & 72.1 & 72.4 & 71.8 \\
\hline Lituania & 71.6 & 71.8 & 70.3 & 70.6 & - & - \\
\hline Italia & 67.2 & 67.8 & 66.3 & 68 & 67.3 & 69.7 \\
\hline Polonia & 72.6 & 71.5 & 68.6 & 70.6 & 71.6 & 69 \\
\hline Francia & 73.8 & 73.4 & 71.8 & 71.3 & 69.8 & 68.8 \\
\hline Finlandia & 69 & 67.5 & 68.5 & 69.3 & 71.5 & 68.5 \\
\hline Rep. Checa & 71.4 & 69.9 & 69 & 70.4 & 68.9 & 68.2 \\
\hline Grecia & 70.6 & 72.2 & 72.4 & 70.2 & 70.5 & 66.9 \\
\hline Países Bajos & 72.5 & 70.2 & 67.8 & 67 & 66.7 & 66.9 \\
\hline Bulgaria & 64.1 & 65 & 64 & 64.1 & 67.1 & 66.6 \\
\hline Irlanda & 70.4 & 71.1 & 69.7 & 69.4 & 68 & 66.6 \\
\hline Eslovaquia & 68.6 & 68.8 & 67.1 & 66.3 & 67.7 & 66.5 \\
\hline UE-27 & 71.1 & 69.8 & 68.2 & 68.3 & 68 & 66.4 \\
\hline Hungría & 63.9 & 65.5 & 64.3 & 65.7 & 65.3 & 66.4 \\
\hline Eslovenia & 78.7 & 78.5 & 76.2 & 64.9 & 61.9 & 65.4 \\
\hline Letonia & 86.9 & 75.9 & 73.1 & 70.3 & 69.5 & 65 \\
\hline Estonia & 64 & 63.7 & 63.3 & 62.6 & 61.9 & 61.7 \\
\hline R. Unido & 65.7 & 67 & 68 & 65.7 & 64.7 & 61.2 \\
\hline Suecia & 68.5 & 64 & 63.1 & 62.4 & 60.4 & 55.9 \\
\hline Rumania & 56.4 & 50.9 & 51.5 & 47.5 & 52.2 & 49.4 \\
\hline España & 51.2 & 45 & 45 & 45.8 & 44.5 & 41 \\
\hline Chipre & 39.9 & 45.2 & 35.6 & 35.6 & 32.7 & 27.4 \\
\hline Portugal & - & - & - & 24.8 & 23 & 20 \\
\hline Malta & 14.5 & 14.9 & 12.9 & 13 & 18.4 & 18.8 \\
\hline Luxemburgo & - & - & - & - & - & - \\
\hline
\end{tabular}

Fuente: ODYSEEE

\section{ESTADO ACTUAL DE LA REGULACIÓN DE LA EFICIENCIA ENERGÉTICA EN ESPAÑA}

Actualmente, las Directivas relativas a la eficiencia energética (Directiva 2002/91/CE y su versión revisada 2010/31/UE y Directiva 2012/27/UE) han influido en los Estados miembros de la UE de manera desigual, en la misma dirección, pero con resultados asimétricos, ya que algunos Estados miembros están más conciencia- 
dos que otros. El estado actual de la aplicación de la Directiva sobre Eficiencia Energética en Edificios (Directive on Energy Performance of Buildings EPDB) se muestra en la Tabla 3.

En España se han realizado una serie de cambios en la legislación relacionada con la eficiencia energética, tales como la aprobación del Código Técnico de la Edificación (CTE), el Real Decreto sobre el Procedimiento básico para la certificación de eficiencia energética de los edificios de nueva construcción (RD 47/2007), aprobado por el Consejo de Ministros el 17 de enero de 2007 y derogado por el RD 235/2013, de 5 de abril, por el que se aprobó el procedimiento básico para la certificación de la eficiencia energética de los edificios de nueva construcción y existentes con un considerable retraso respecto a nuestros vecinos europeos, y la revisión del Reglamento de Instalaciones Térmicas en edificios (RITE). Las principales regulaciones europeas son la Directiva 2002/91/CE, la Directiva 2010/31/UE, el Reglamento 244/2012 y la Directiva 2012/27/UE.

Tabla 3. Implementación de EPDB en los Estados Miembros de la UE

\begin{tabular}{|c|c|c|c|c|c|}
\hline $\begin{array}{l}\text { Estado } \\
\text { Miembro }\end{array}$ & $\begin{array}{l}\text { Implementación } \\
\text { de la EPBD }\end{array}$ & $\begin{array}{l}\text { Nueva } \\
\text { edificación } \quad \text { y } \\
\text { reformas } \\
\text { importantes }\end{array}$ & $\begin{array}{l}\text { Inmuebles a } \\
\text { la venta o } \\
\text { en alquiler }\end{array}$ & Etiquetas & $\begin{array}{l}\text { Validez del } \\
\text { Certificado } \\
\text { Energético }\end{array}$ \\
\hline España & 2007 / 2013 & Desde 2007 & $\begin{array}{l}\text { Desde } \\
06 / 2013\end{array}$ & $\begin{array}{l}\text { Desde A hasta } \\
\text { G }\end{array}$ & 10 años \\
\hline Portugal & 2006 & Desde 07/2007 & $\begin{array}{l}\text { Desde } \\
01 / 2009\end{array}$ & $\begin{array}{l}\text { Desde A hasta } \\
\text { G }\end{array}$ & $\begin{array}{l}10 \text { años / } 6 \text { años } \\
\text { en edificios } \\
\text { públicos }\end{array}$ \\
\hline Italia & $2005 / 2010$ & Desde 07/2009 & 2009 & $\begin{array}{l}\text { Desde A+ hasta } \\
G\end{array}$ & 10 años \\
\hline $\begin{array}{l}\text { Reino } \\
\text { Unido }\end{array}$ & 2007 / 2010 & Desde 2008 & 2008 & $\begin{array}{l}\text { Desde } 1 \text { hasta } \\
100\end{array}$ & 10 años \\
\hline Alemania & $2002 / 2007$ & Desde 2002 & 2009 & $\begin{array}{l}\text { Desde } 0 \text { hasta } \\
>400 \\
\mathrm{kWh} /\left(\mathrm{m}^{2 *} \mathrm{a}\right)\end{array}$ & 10 años \\
\hline Francia & $2005 / 2010$ & Desde 2006 & 2007 & $\begin{array}{l}\text { Desde A hasta } \\
G\end{array}$ & 10 años \\
\hline Austria & 2008 & $>\mathrm{C}$ & $\begin{array}{l}\text { Desde } \\
05 / 2008\end{array}$ & $\begin{array}{l}\text { Desde } \\
\text { hasta G }\end{array}$ & 10 años \\
\hline
\end{tabular}

Fuente: Elaboración propia.

A continuación, se describen las principales normativas españolas (en vigor) relacionadas con el tema:

- Real Decreto 314/2006, de 17 de marzo, que aprueba el Código Técnico de la Edificación (CTE) [15] aplica la EPBD directamente mediante su artículo 15 sobre el Ahorro de Energía (HE). Se establecen directrices que contienen procedimientos, reglas técnicas y ejemplos de soluciones para la determinar si un edificio cumple con unos niveles mínimos esta- 
blecidos. Los requisitos básicos de ahorro de energía (HE) cubren los siguientes temas:

o HE1: Limitación de demanda energética. Por el cual, los edificios dispondrán de una envolvente de características tales que limiten adecuadamente la demanda energética necesaria para alcanzar el bienestar térmico en función del clima de la localidad, del uso del edificio y del régimen de verano y de invierno, así como por sus características de aislamiento e inercia, permeabilidad al aire y exposición a la radiación solar, reduciendo el riesgo de aparición de humedades de condensación superficiales e intersticiales que puedan perjudicar sus características y tratando adecuadamente los puentes térmicos para limitar las pérdidas o ganancias de calor y evitar problemas higrotérmicos en los mismos.

o HE2: Rendimiento de las instalaciones térmicas. Por el cual, los edificios dispondrán de instalaciones térmicas apropiadas destinadas a proporcionar el bienestar térmico de sus ocupantes. Esta exigencia se desarrolla en el Reglamento de Instalaciones Térmicas en los Edificios, RITE.

o HE3: Eficiencia energética de las instalaciones de iluminación. Por el cual, los edificios dispondrán de instalaciones de iluminación adecuadas a las necesidades de sus usuarios y a la vez eficaces energéticamente disponiendo de un sistema de control que permita ajustar el encendido a la ocupación real de la zona, así como de un sistema de regulación que optimice el aprovechamiento de la luz natural, en las zonas que reúnan unas determinadas condiciones.

o HE4: Contribución solar mínima de agua caliente sanitaria. Por el cual, en los edificios con previsión de demanda de agua caliente sanitaria o de climatización de piscina cubierta, una parte de las necesidades energéticas térmicas derivadas de esa demanda se cubrirá mediante la incorporación en los mismos de sistemas de captación, almacenamiento y utilización de energía solar de baja temperatura adecuada a la radiación solar global de su emplazamiento y a la demanda de agua caliente del edificio o de la piscina.

o HE5: Contribución fotovoltaica mínima de energía eléctrica. Por el cual, en determinados edificios se incorporarán sistemas de captación y transformación de energía solar en energía eléctrica por procedimientos fotovoltaicos para uso propio o suministro a la red.

- Real Decreto 47/2007, de 19 de enero, por el que se aprueba el Procedimiento básico para la certificación de eficiencia energética de edificios de nueva construcción [17] establecía el marco jurídico para la certificación de eficiencia energética en nuevos edificios. Se evaluaba el consumo de energía primaria anual del edificio, y la calificación energética dadas las emisiones globales de $\mathrm{CO}_{2}$. La escala de calificación energética en España varía de A (muy alto rendimiento, con un gran aporte de las 
energías renovables) a $\mathrm{G}$ (bajo rendimiento). Esta clasificación depende de las emisiones globales del edificio. Esta certificación energética eran, según este derogado Real Decreto, obligatoria para todos los edificios nuevos y grandes reformas (si el cambio en la envolvente del edificio es de más del $25 \%$ o del presupuesto total de la reforma es superior que el costo de la construcción).

- El Ministerio de Industria, Energía y Turismo a través del Instituto para la Diversificación y Ahorro de la Energía, IDAE contribuye a la consecución de los objetivos que tiene adquiridos España en materia de eficiencia energética, energías renovables y otras tecnologías bajas en carbono. El IDAE con el Real Decreto-ley 20/2012, de 13 de julio, amplia sus competencias dando apoyo a las tecnologías orientadas a la descarbonización de la generación eléctrica; prestar asistencia al Ministerio de Industria, Energía y Turismo en procedimientos administrativos, judiciales o arbitrales en los que sea parte la Administración General del Estado; y desarrollar como medio propio instrumental y servicio técnico, así como proporcionar a los técnicos competentes nuevos software para el cálculo de los certificados de eficiencia energética por cualquiera de los dos métodos posibles (simplificado y general).

- Real Decreto 1027/2007 de 20 de julio, que aprueba el Reglamento de Instalaciones Térmicas de los Edificios (RITE) [18] revisada en el Real Decreto 238/2013 de 5 de abril [19] donde se establece las condiciones que deben cumplir calefacción, refrigeración e instalaciones de agua caliente sanitaria para el bienestar térmico e higiene, a fin de lograr un uso racional de la energía. Esta ley cubre los siguientes aspectos de los sistemas de calefacción en los edificios: comodidad e higiene, requisitos de eficiencia energética, requisitos de seguridad, montaje, mantenimiento y uso, la inspección de la construcción de sistemas térmicos, y los reglamentos disciplinarios.

- Real Decreto 235/2013, de 5 de abril, por el que se aprueba el procedimiento básico para la certificación de la eficiencia energética de los edificios [20] que transpone la Directiva 2010/31/UE en lo relativo a la eficiencia energética de edificios y refunde el Real Decreto 47/2007, de 19 de enero, con la incorporación del Procedimiento básico para la certificación de eficiencia energética de edificios existentes. Regulando las certificaciones energéticas de los edificios existentes y de nueva construcción. Esta normativa es la primera en ser de aplicación para edificios existentes. En concreto, es obligatorio desde el 1 de junio del 2013 que todo inmueble en alquiler o en venta disponga de un certificado energético registrado en el órgano competente de la Comunidad Autónoma, además de edificios o partes de edificios en los que una autoridad pública ocupe una superficie útil total superior a $250 \mathrm{~m}^{2}$ y que sean frecuentados habitualmente por el público. 
La Certificación Energética en los edificios de nueva construcción (residencial y terciario) es obligatoria desde el 31 de octubre de 2007. Mientras que los edificios existes, es obligatoria para inmuebles en venta o alquiler desde el 1 de Junio del 2013, tras la aprobación del Real Decreto 235/2013. Los métodos actualmente en uso para el cálculo de la efíciencia energética están regulados en el RD 235/2013, denominado "procedimiento básico para la certificación de la eficiencia energética de los edificios", ofreciendo dos métodos posibles, simplificado y general, para la certificación energética.

Este procedimiento de certificación es de aplicación a los inmuebles (ya sean viviendas individuales, oficinas, locales o edificios con uso residencial o terciario) a nivel nacional con diferentes características dependiendo de la severidad climática. España se encuentra dividida en 12 zonas climáticas según la tabla D.1 del Código Técnico de la Edificación, Documento Básico de Ahorro de Energía 1 (CTE DB HE 1) (Figura 2) [15]. La zona climática de cualquier localidad que no aparezca en la tabla se determina según el desnivel a la capital de provincia.

Para localidades con climas que muestren fuertes contrastes, la zona climática se calcula a partir de sus temperaturas extremas de verano y de invierno: La severidad climática de una localidad es el cociente entre la demanda energética de un edificio cualquiera en dicha localidad y la correspondiente al mismo edificio en una localidad de referencia. En la reglamentación española se ha tomado Madrid como localidad de referencia, siendo, por tanto, su severidad climática la unidad. Se define una severidad climática para verano y una para invierno. La severidad climática combina los grados-día y la radiación solar de la localidad, de forma que se puede demostrar que cuando dos localidades tienen la misma severidad climática de invierno (SCI) la demanda energética de calefacción de un mismo edificio situado en ambas localidades es sensiblemente igual. Lo mismo es aplicable para la severidad climática de verano (SCV). Para invierno se definen cinco divisiones distintas correspondientes a los valores de la A-E. Para verano se definen 4 divisiones distintas del 1-4. Combinando las 5 divisiones de invierno con las 4 de verano se obtendrían 20 zonas distintas, de las cuales únicamente 12 cumplen con las condiciones ambientales de la geografía española.

La ciudad de Almería y localidades de la provincia con cotas hasta 200 metros de altura están clasificadas como A4, siendo la única zona en la geografía española con dicha clasificación. El "4" significa que el clima es severo en el verano y la "A" que tiene inviernos suaves. El clima de Almería es mediterráneo seco, y se caracteriza por la escasez de lluvias, inviernos suaves sin congelación y veranos con altas temperaturas y humedad. La temperatura media anual es de $19^{\circ} \mathrm{C}$ y la precipitación total si 145 $\mathrm{mm}$.

Según las zonas climáticas, existen grandes diferencias en las soluciones constructivas en la edificación. Además, hay que considerar la evolución histórica de los materiales y sistemas, producto de los cambios de normativas que pretendían mejorar la calidad de vida de sus ocupantes y disminuir pérdidas de energía. Es decir, ahorrar dinero durante la vida útil del edificio obligando a realizar una inversión inicial mayor 
durante su construcción (como por ejemplo la colocación de placas solares para agua caliente sanitaria).

Figura 2. Zonas climáticas de España consideradas en el CTE.
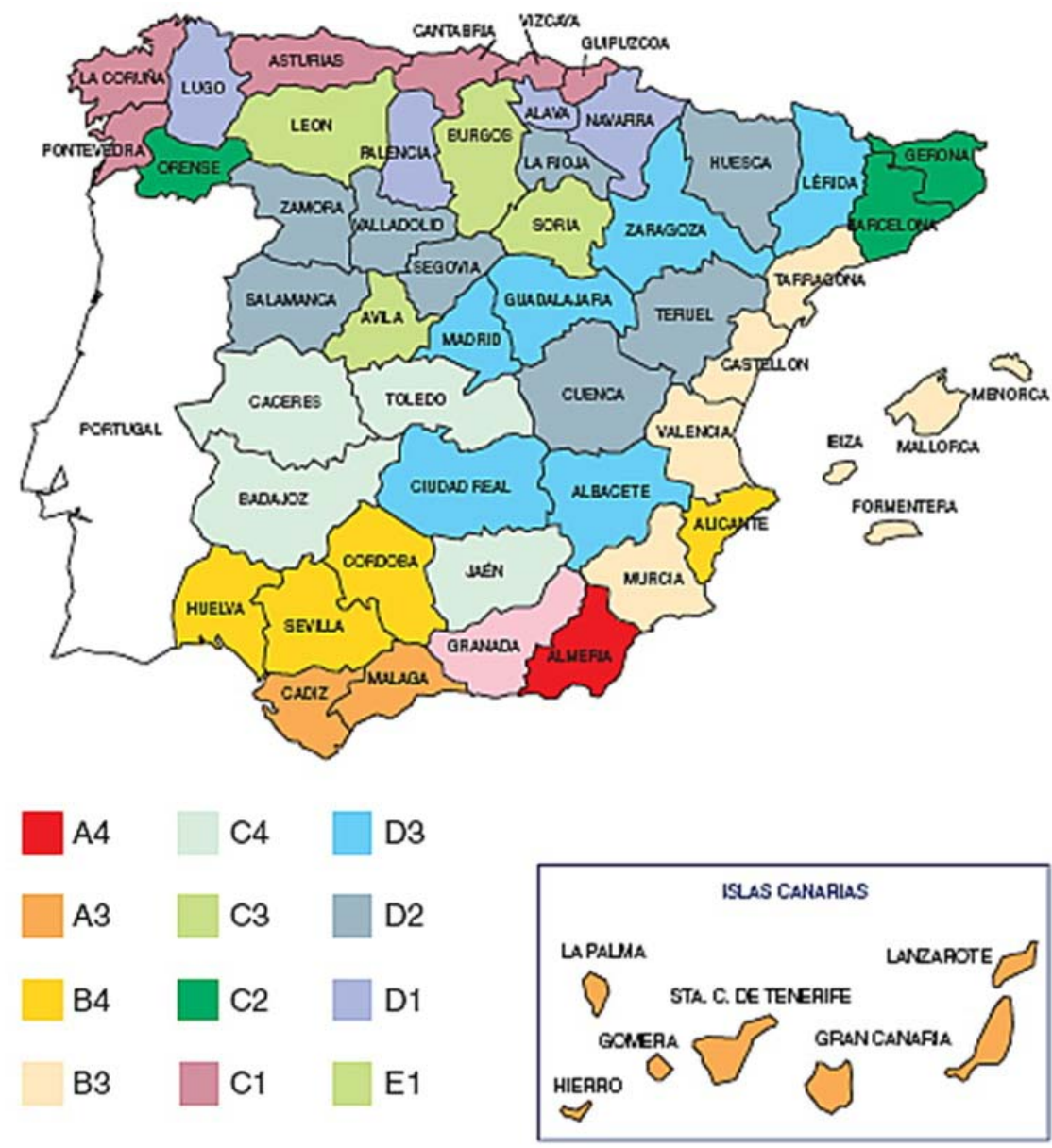

Fuente: Centro nacional de Energías Renovables (Fundación Cener-Ciemat)

\section{EVOLUCIÓN DE LOS MÉTODOS CONSTRUCTIVOS}

El sector de la edificación, a diferencia de la industria, ha tenido una evolución lineal, es decir, se ha seguido construyendo más o menos con los mismos sistemas constructivos que hace 25 años, y los cambios que han ocurrido han sido provocados por el aumento de la rigurosidad en la normativa. Produciéndose los mayores cambios 


\section{con la entrada en vigor del Código Técnico de la Edificación (RD 314/2006 de 17 de marzo), y en concreto del Documento Básico de Ahorro de Energía (CTE DB HE).}

\section{Tabla 4. Características de los sistemas constructivos en la zona A4.}

\begin{tabular}{|c|c|c|c|}
\hline & $1988-1994$ & $1995-2006$ & 2007 - actualmente \\
\hline $\begin{array}{l}\text { Ventanas y } \\
\text { puertas } \\
\text { exteriores }\end{array}$ & $\begin{array}{l}\text { - De aluminio sin rotura } \\
\text { de puente térmico, y } \\
\text { sistema de apertura tipo } \\
\text { correderas. } \\
\text { - Vidrio sencillo de } 4 \text { o } \\
6 \mathrm{~mm} \text {. }\end{array}$ & $\begin{array}{l}\text { - De aluminio sin rotura } \\
\text { de puente térmico, y } \\
\text { sistema de apertura tipo } \\
\text { correderas o batientes. } \\
\text { - Vidrio doble compuesto } \\
\text { por } 4 \mathrm{~mm} \mathrm{de} \mathrm{vidrio} \\
\text { interior, } 6 \mathrm{~mm} \text { de cámara } \\
\text { de aire y } 4 \mathrm{~mm} \text { de vidrio } \\
\text { exterior. }\end{array}$ & $\begin{array}{l}\text { - De Policloruro de vinilo } \\
\text { (PVC) con dos cámaras o } \\
\text { aluminio con rotura de puente } \\
\text { térmico entre } 4 \text { a } 12 \mathrm{~mm} \text {. } \\
\text { - Vidrios dobles en posición } \\
\text { vertical compuesto por } 4 \mathrm{~mm} \\
\text { de vidrio interior, } 6 \mathrm{~mm} \mathrm{de} \\
\text { cámara de aire y } 4 \mathrm{~mm} \mathrm{de} \\
\text { vidrio exterior. }\end{array}$ \\
\hline $\begin{array}{l}\text { Paredes } \\
\text { exteriores }\end{array}$ & $\begin{array}{l}\text { - } 10 \mathrm{~mm} \text { de mortero de } \\
\text { cemento, } 120 \mathrm{~mm} \text { de } \\
\text { ladrillo hueco, cámara } \\
\text { de aire de } 50 \mathrm{~mm} \text { sin } \\
\text { aislante, trasdosado de } \\
\text { ladrillo de hueco } \\
\text { sencillo de } 40 \mathrm{~mm} \\
\text { terminado en } 10 \mathrm{~mm} \mathrm{de} \\
\text { yeso enlucido. }\end{array}$ & $\begin{array}{l}\text { - Cerramiento exterior } \\
\text { compuesto por } 10 \mathrm{~mm} \text { de } \\
\text { mortero de cemento, } \\
120 \mathrm{~mm} \text { de ladrillo hueco, } \\
\text { cámara de aire de entre } 30 \\
\text { a } 50 \mathrm{~mm} \text { con aislante de } \\
\text { espuma de poliuretano, } \\
\text { lana de vidrio o } \\
\text { poliestireno de } 30 \mathrm{~mm} \text {, } \\
\text { trasdosado de ladrillo de } \\
\text { hueco sencillo de } 40 \mathrm{~mm} \\
\text { terminado en } 10 \mathrm{~mm} \mathrm{de} \\
\text { yeso enlucido. }\end{array}$ & $\begin{array}{l}\text { - Fachada compuesta por: } \\
15 \mathrm{~mm} \text { de mortero de cemento, } \\
115 \mathrm{~mm} \text { de ladrillo perforado, } \\
16 \mathrm{~mm} \text { de EPS poliestireno } \\
\text { expandido }\left(0.029 \mathrm{~W} / \mathrm{m}^{2} \mathrm{~K}\right) \text {, } \\
\text { cámara de aire de } 50 \mathrm{~mm} \text { en } \\
\text { posición vertical, } 40 \mathrm{~mm} \text { de } \\
\text { ladrillo hueco sencillo } \\
\text { terminado en } 5 \mathrm{~mm} \text { de enlucido } \\
\text { de yeso. [Con un U }= \\
\left.0,92 \mathrm{~W} / \mathrm{m}^{2} \mathrm{~K} .\right]\end{array}$ \\
\hline Forj & $\begin{array}{l}\text { - } r \text { Forjados } \\
\text { unidireccionales } \\
\text { formado con viguetas } \\
\text { con bovedillas de } \\
\text { hormigón de } 200 \mathrm{~mm} \\
\text { terminados en capa de } \\
\text { compresión de } 50 \mathrm{~mm} \text {. }\end{array}$ & $\begin{array}{l}\text { Similar al período } \\
\text { anterior. }\end{array}$ & $\begin{array}{l}\text { - Suelos en contacto } \\
\text { terreno o con } \\
\text { calefactado compuesto por } \\
\text { forjado unidireccional con } \\
\text { entrevigado cerámico y canto } \\
250 \mathrm{~mm} \text { aislante compuesto } \\
\text { por placa de EPS poliestireno } \\
\text { expandido de } 40 \mathrm{~mm} \\
\left(0.029 \mathrm{~W} / \mathrm{m}^{2} \mathrm{~K}\right), 20 \mathrm{~mm} \text { de } \\
\text { mortero de cemento y } \\
\text { terminado en baldosa } \\
\text { cerámica. [Con un U }= \\
\left.0,53 \mathrm{~W} / \mathrm{m}^{2} \mathrm{~K} .\right]\end{array}$ \\
\hline Cubiertas & $\begin{array}{l}\text { Cubierta formada por } \\
\text { forjado unidireccional } \\
\text { de } 200 \mathrm{~mm} \text { con } 50 \mathrm{~mm} \text { de } \\
\text { capa de compresión, } \\
\text { sobre la cual se hace la } \\
\text { formación de pendiente } \\
\text { con hormigón aligerado, } \\
\text { y baldosa cerámica. }\end{array}$ & $\begin{array}{l}\text { - Similar al período } \\
\text { anterior. }\end{array}$ & $\begin{array}{l}\text { - Cubierta compuesta por: } \\
\text { forjado unidireccional con } \\
\text { entrevigado cerámico y canto } \\
250 \mathrm{~mm} \text { formación de } \\
\text { pendiente con hormigón } \\
\text { aligerado con un espesor } \\
\text { mínimo de } 70 \mathrm{~mm} \text {, aislante } \\
\text { compuesto por placa de EPS } \\
\text { poliestireno expandido de } \\
45 \mathrm{~mm}\left(0.029 \mathrm{~W} / \mathrm{m}^{2} \mathrm{~K}\right), 15 \mathrm{~mm} \\
\text { de mortero de cemento y } \\
\text { terminado en baldosa } \\
\text { cerámica. [Con un U = } \\
\left.0,50 \mathrm{~W} / \mathrm{m}^{2} \mathrm{~K} .\right] \text {. }\end{array}$ \\
\hline
\end{tabular}

Fuente: Elaboración propia. 
En el caso de la zona climática A4, para determinar la evolución de los sistemas constructivos se han estudiado las memorias constructivas de 500 inmuebles de diferentes años y calidades, provenientes de valoraciones inmobiliarias y contrastadas con profesionales del sector (Arquitectos Técnicos y Arquitectos).

En la zona A4 (localidades en la provincia de Almería con una altura sobre el mar inferior a $200 \mathrm{~m}$ ), en los últimos 25 años la evolución de los sistemas constructivos es lineal hasta la entrada del Código Técnico de la Edificación (RD 314/2006 de 17 de marzo) y en concreto del Documento Básico de Ahorro de Energía (CTE DB HE).

En los últimos 25 años se han determinado dos cambios significativos en los elementos constructivos, para inmuebles de calidad media-baja en la zona A4, pudiendo dividirlos en tres periodos que comprenderían los años del 1988 al 1995, del 1995 al 2007 y del 2007 hasta la fecha (posteriores al CTE). Las principales características que lo determinan cada uno de estos periodos son mostrados en la Tabla 4.

En resumen, el CTE DB HE 1 obliga a que los edificios dispongan de un envolvente que limite, de manera adecuada, la demanda energética necesaria para alcanzar el bienestar térmico, en función del clima de la localidad, del uso del edificio y del régimen de verano y de invierno. Así como también, en función de sus características de aislamiento e inercia, permeabilidad al aire y exposición a la radiación solar, de manera que se reduzca el riesgo de aparición de humedades de condensación superficiales e intersticiales que puedan perjudicar sus características. Además, obliga que se trate adecuadamente los puentes térmicos para limitar las pérdidas o ganancias de calor y evitar problemas higrotérmicos en los mismos.

En la zona A4, las limitaciones de coeficiente de transmitancia térmica máxima de cerramientos y particiones interiores de la envolvente térmica $U\left(e n t / \mathrm{m}^{2} \mathrm{~K}\right)$ es de 0.94 para muros de fachada y cerramientos en contacto con el terreno, 0.53 para suelos, 0.50 para cubiertas, entre 5.7 y 3.4 para vidrios y marcos en función de la orientación y del porcentaje de huecos, y de 1.22 para medianerías. Estas limitaciones han obligado a tener que cambiar la manera de construir, empezando a introducir aislantes y a aumentar espesores (ver tabla 4).

\section{METODOLOGÍA PARA EL ANÁLISIS DEL CAMBIO DE NORMATIVA Y MÉTODOS CONSTRUCTIVOS}

El presente estudio se ha realizado sobre una promoción de viviendas existente, que fue edificada en el año 2001. La promoción de viviendas se localiza en el término municipal de Almería (36 51' $25^{\prime \prime} \mathrm{N}, 2^{\circ} 26^{\prime} 44^{\prime \prime} \mathrm{W}$ ) sobre una parcela de $10718 \mathrm{~m}^{2}$. Esta promoción consta de once bloques con diferentes características, que reflejan una amplia casuística de orientaciones y superficies. En la Figura 3 se observa la localización de la promoción de viviendas, y un esquema tipo de sus bloques. 
Figura 3. Localización y esquema tipo de la promoción de viviendas seleccionada.
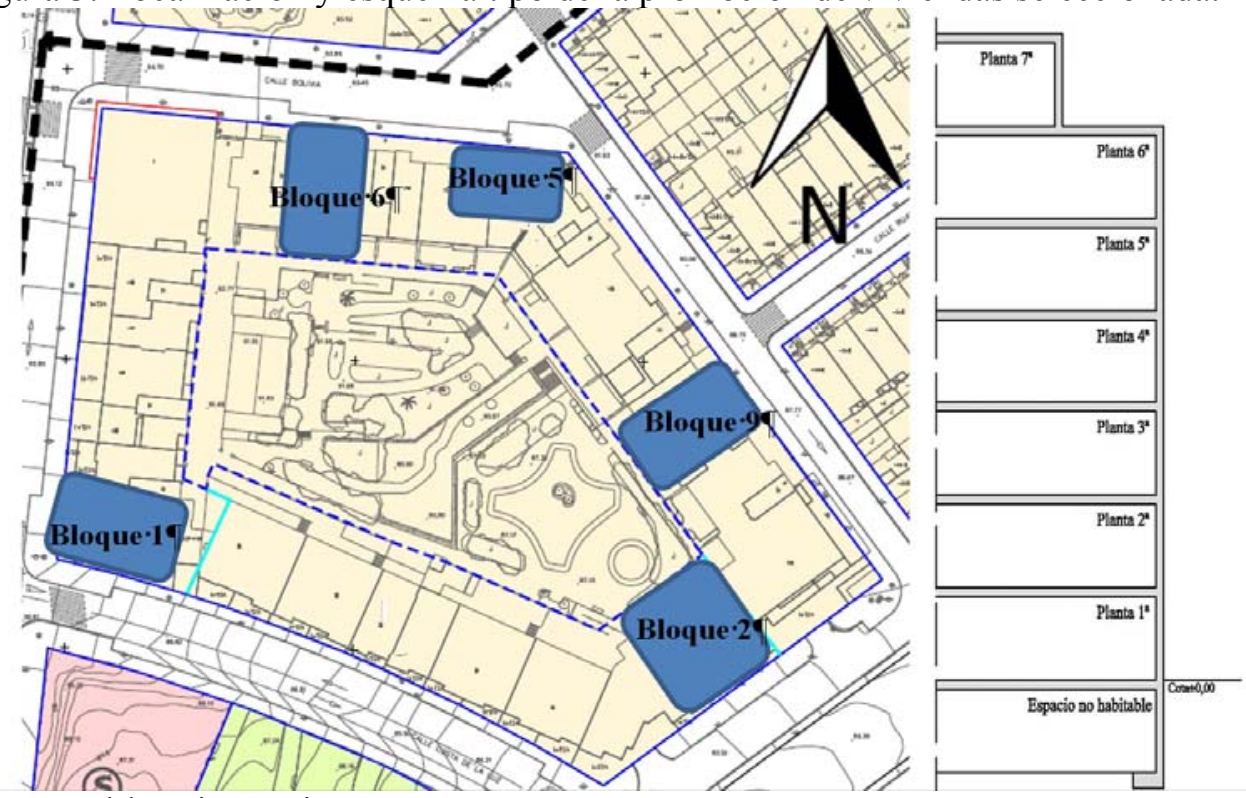

Fuente: Elaboración propia.

Para el estudio, se seleccionaron 5 de los 11 bloques que componen la promoción (Tabla 5), y de ellos, se analizó el efecto de los cambios en los métodos constructivos de las viviendas ubicadas en las siguientes plantas: planta baja (en contacto con local no calefactado), quinta planta (entre viviendas), sexta planta (similar a la quinta planta, pero con un porcentaje de su techo en contacto con el patio del ático) y séptima planta (ático). En el caso del Bloque 5, únicamente se tomaron primera, quinta y sexta porque parte de la séptima planta corresponde a la terraza del ático del bloque contiguo.

Tabla 5. Características de los bloques seleccionados.

\begin{tabular}{|c|c|c|c|c|c|c|}
\hline $\begin{array}{l}\mathrm{N}^{\circ} \text { de } \\
\text { bloque }\end{array}$ & $\begin{array}{l}\text { Via } \\
\text { principal }\end{array}$ & $\begin{array}{l}\text { Orientación } \\
\text { principal }\end{array}$ & $\begin{array}{l}\text { Orientación } \\
\text { secundaria }\end{array}$ & $\begin{array}{l}\text { Plantas } \\
\text { seleccionadas }\end{array}$ & $\begin{array}{l}\text { Superficie } \\
\text { media }\left(\mathbf{m}^{2}\right)\end{array}$ & $\begin{array}{l}\text { Superficie } \\
\text { media de } \\
\text { fachada } \\
\left(\mathrm{m}^{2}\right)\end{array}$ \\
\hline 1 & $\begin{array}{l}\text { Costa de } \\
\text { la Luz }\end{array}$ & Sur & Sur - oeste & $1^{\mathrm{a}}, 5^{\mathrm{a}}, 6^{\mathrm{a}}, 7^{\mathrm{a}}$ & 78 & 60 \\
\hline 2 & $\begin{array}{l}\text { Costa de } \\
\text { la Luz }\end{array}$ & Norte- este & Sur - este & $1^{\mathrm{a}}, 5^{\mathrm{a}}, 6^{\mathrm{a}}, 7^{\mathrm{a}}$ & 80 & 61 \\
\hline 5 & $\begin{array}{l}\text { Calle } \\
\text { Bolivia }\end{array}$ & Norte & Norte-este & $1^{\mathrm{a}}, 5^{\mathrm{a}}, 6^{\mathrm{a}}$ & 78 & 60 \\
\hline 6 & $\begin{array}{l}\text { Calle } \\
\text { Bolivia }\end{array}$ & Norte- este & Sur - oeste & $1^{\mathrm{a}}, 5^{\mathrm{a}}, 6^{\mathrm{a}}, 7^{\mathrm{a}}$ & 111 & 60 \\
\hline 9 & $\begin{array}{l}\text { Calle } \\
\text { Bosnia }\end{array}$ & Norte- este & Sur - oeste & $1^{\mathrm{a}}, 5^{\mathrm{a}}, 6^{\mathrm{a}}, 7^{\mathrm{a}}$ & 111 & 60 \\
\hline
\end{tabular}

Fuente: Elaboración propia. 
De la inspección técnica para la certificación energética de las viviendas se han obtenido los siguientes datos: la superficie útil de vivienda; superficie y orientación de fachada; porcentaje de huecos; composición de la fachada, suelo, techo y huecos; sistemas de refrigeración, calefacción y ACS; sombras determinantes; y, puentes térmicos determinantes.

A partir de estos datos se procedió a calcular el Indicador Energético Global $\left(\mathrm{IEE}_{\mathrm{G}}\right)$, de acuerdo con la metodología establecida en el DB-HE1 del CTE. Los datos necesarios para su cálculo son las emisiones anuales de $\mathrm{CO}_{2}$, expresadas en $\mathrm{kg} \mathrm{m}^{-2}$ de superficie útil del edifico y la energía primaria anual, expresada en $\mathrm{kWh} \mathrm{m}^{-2}$ de superficie útil del edificio. También, se calcularon los indicadores energéticos complementarios: emisiones de $\mathrm{CO}_{2}$, consumo de energía primaria, y energía demandada por la vivienda para los servicios principales del edificio. Estos indicadores se obtuvieron tanto en base anual, como referidos a la unidad de superficie útil $\left(\mathrm{m}^{2}\right)$ del edificio para sus servicios principales, calefacción, refrigeración y ACS.

Los cálculos se realizaron mediante los programas informáticos desarrollados por el Instituto para la Diversificacion y Ahorro de la Energía (IDAE), a petición del Ministerio de Industria del Gobierno de España. Los programas LIDER+CALENER permiten el cálculo de la eficiencia energética por método general para edificios de nueva construcción. Determinan el nivel de eficiencia energética y asignan una calificación simbolizada por una letra entre la A y la E. Aunque la normativa exige que la calificación sea entre A y G, reduce las clases de calificación al centrarse en viviendas de nueva construcción.

Para calificar la eficiencia energética de los inmuebles existentes con letras entre A y $\mathrm{G}$, se desarrollaron los programas $\mathrm{Ce} 3$ y Ce3x. Estos programas aplican el método simplificado de certificación de eficiencia energética, creando un edificio de referencia con la misma zona climática, dimensión, orientación de fachadas y relación vidrio/muro, periodo, uso, sistemas de climatización y de ACS. Permitiendo modificar los elementos constructivos originales a unos de referencia, facilitando las comparaciones de los supuestos con el original, que determinan el $\mathrm{IEE}_{\mathrm{G}} \mathrm{y}$ la calificación de la eficiencia energética de los supuestos.

Las ventajas de usar un método simplificado son la disminución del tiempo de introducción de factores, y por tanto existe un aumento de la velocidad con la que el programa arroja resultados, y que a diferencia del método general, este método está enfocado a edificios existentes, por lo tanto califica los inmuebles de la $\mathrm{A}$ a la $\mathrm{G}$. Como desventajas se señala: la pérdida de precisión porque sus cálculos van a favor de la seguridad. En los test oficiales comparativos de precisión de Ce3 para viviendas en bloque en la zona climática A4 se observó que: el $0.14 \%$ de las veces mejora la calificación en una letra, el $70.45 \%$ coincide la letra, el $29.38 \%$ rebaja la calificación en una letra, y el $0.02 \%$ mejora la calificación en dos letras.

Para poder usar el método simplificado deben de cumplirse que:

- La superficie de huecos en cada fachada sea inferior al $60 \%$ de su superficie, salvo que el área de la fachada suponga un porcentaje menor del 10\% del área total de las fachadas del edificio. 
- La superficie de lucernarios sea inferior al 5\% de la superficie total de la cubierta.

- El edificio disponga de cerramientos formados por soluciones constructivas no convencionales.

Una vez calculados los indicadores de las viviendas de la promoción existente (periodo 1995-2006), se cambiaron las calidades constructivas y sistemas de calefacción, refrigeración y ACS, en función de los elementos constructivos enunciados en la Tabla 4. En la Tabla 6 se indican los sistemas y coeficientes de transmitancia térmica para esos elementos constructivos.

Tabla 6. Sistemas y coeficientes de transmitancia térmica de los elementos constructivos.

\begin{tabular}{|c|c|c|c|}
\hline & 1988 - 1994 & $1995-2006$ & $\begin{array}{l}2007 \text { - hasta la } \\
\text { actualidad }\end{array}$ \\
\hline $\begin{array}{lll}\begin{array}{l}\text { Ventanas } \\
\text { exteriores }\end{array} & \text { y } & \text { puertas } \\
\end{array}$ & $\mathrm{U}=5.70 \quad\left[\mathrm{~W} / \mathrm{m}^{2} \cdot \mathrm{K}\right]$ & $\mathrm{U}=3.54 \quad\left[\mathrm{~W} / \mathrm{m}^{2} \cdot \mathrm{K}\right]$ & $\mathrm{U}=2,92 \quad\left[\mathrm{~W} / \mathrm{m}^{2} \cdot \mathrm{K}\right]$, \\
\hline Cerramiento exterior & $\mathrm{U}=1.80\left[\mathrm{~W} / \mathrm{m}^{2} \bullet \mathrm{K}\right]$ & $\mathrm{U}=1.03\left[\mathrm{~W} / \mathrm{m}^{2} \bullet \mathrm{K}\right]$ & $\mathrm{U}=0.92 \mathrm{~W} / \mathrm{m}^{2} \mathrm{~K}$ \\
\hline Forjados & $\mathrm{U}=2.47\left[\mathrm{~W} / \mathrm{m}^{2} \bullet \mathrm{K}\right]$ & $\mathrm{U}=2.06\left[\mathrm{~W} / \mathrm{m}^{2} \bullet \mathrm{K}\right]$ & $\mathrm{U}=0.53 \mathrm{~W} / \mathrm{m}^{2} \mathrm{~K}$ \\
\hline Cubierta & $\mathrm{U}=1.40\left[\mathrm{~W} / \mathrm{m}^{2} \bullet \mathrm{K}\right]$ & $\mathrm{U}=1.34\left[\mathrm{~W} / \mathrm{m}^{2} \bullet \mathrm{K}\right]$ & $\mathrm{U}=0.50 \mathrm{~W} / \mathrm{m}^{2} \mathrm{~K}$ \\
\hline (Acumulador & $1.2 \mathrm{~kW}$ & $1, \quad 1,6 \mathrm{~kW}$ & $1,6 \mathrm{~kW}$, \\
\hline $\begin{array}{l}\text { Térmico) } \\
\text { Contribución } \\
\text { minima }\end{array}$ & $\begin{array}{l}\text { Rendimiento }=97 \% \\
0 \% .\end{array}$ & $\begin{array}{l}\text { Rendimiento }=98 \% \\
0 \% .\end{array}$ & $\begin{array}{l}\text { Rendimiento }=98 \% \\
70 \% \text {. }\end{array}$ \\
\hline
\end{tabular}

Fuente: Elaboración propia.

Finalmente, los datos de los indicadores energéticos calculados fueron analizados estadísticamente para determinar la influencia de los cambios en los métodos constructivos en la zona climática española A4. La influencia se determinó a través del cálculo de la correlación existente entre los indicadores energéticos y las superficies donde se puedan producir pérdida o ganancia de energía: fachada total, suelo con local no habitable y cubierta.

A continuación, en la Tabla 7 se muestran, a modo de ejemplo, los resultados obtenidos al realizar la certificación energética a una de las viviendas en planta ático construida en el 2001. Las características de las viviendas son: $117 \mathrm{~m}^{2}$ útiles, $92 \mathrm{~m}^{2} \mathrm{de}$ fachada total orientadas a Noreste y Suroeste con $\mathrm{U}=1.03 \mathrm{~W} / \mathrm{m}^{2} \cdot \mathrm{K}$ y un $17.4 \%$ de huecos con $\mathrm{U}=3.54 \mathrm{~W} / \mathrm{m}^{2} \bullet \mathrm{K}$ y Factor Solar $=0.69 ; 117 \mathrm{~m}^{2}$ de cubierta con $\mathrm{U}=1.34$ $\mathrm{W} / \mathrm{m}^{2} \bullet \mathrm{K}$. Para el sistema de ACS se usa un termoacumulador eléctrico de 80 litros con una potencia de $1.6 \mathrm{~kW}$ y un rendimiento del $98 \%$ y climatización para el $100 \%$ del inmueble con un ERR de 3 y COP de 3.15 .

\section{RESULTADOS Y DISCUSIÓN}

Las certificaciones energéticas de las 19 viviendas de la promoción existente construida en 2001 (Tabla 8), dio como resultado una calificación E y F para nueve 
de ellas, cada una,y $\mathrm{G}$ para las restantes. Por planta, todas las quintas plantas (entre plantas calefactadas) tuvieron una calificación $\mathrm{E}$, los áticos (séptima planta) y plantas con superficie de cubierta una calificación de entre E y F, y las plantas con la superficie de suelo sobre local no calefactado obtuvieron una calificación $F$ (con excepción de una vivienda que obtuvo G).

Considerando los métodos constructivos de 1991, dos de los áticos reducirían su calificación a $\mathrm{G}$, la calificación de las plantas con superficie de cubierta se mantienen constantes el $80 \%$ y en el $20 \%$ baja en una letra. Los inmuebles entre plantas calefactadas tendrían la misma calificación, y los inmuebles sobre locales no calefactados reducirían su calificación en una letra (Tabla 9).

Tabla 7. Ejemplo de resultados obtenidos de cada una de las certificaciones realizadas.

CALIFICACIÓN ENERGÉTICA DE VIVIENDA TIPO PISO EXISTENTE

Resultados en la situación actual

\begin{tabular}{l|l|l|l|}
\cline { 2 - 4 } & Calefacción & Refrigeración & A,C,S, \\
\hline $\begin{array}{l}\text { Demanda de Energía } \\
\left(\mathrm{kWh} / \mathrm{m}^{2}\right)\end{array}$ & 49,72 & 23,09 & 12,31 \\
\hline $\begin{array}{l}\text { Consumo de energía } \\
\text { final }\left(\mathrm{kWh} / \mathrm{m}^{2}\right)\end{array}$ & 27,93 & 16,01 & 12,56 \\
\hline $\begin{array}{l}\text { Consumo de energía } \\
\text { rrimaria }\left(\mathrm{kWh} / \mathrm{m}^{2}\right)\end{array}$ & 72,89 & 41,78 & 32,79 \\
\hline $\begin{array}{l}\text { Emisiones de CO } \\
\left(\mathrm{kg} \mathrm{CO} / \mathrm{m}^{2}\right)\end{array}$ & 18,13 & 10,39 & 8,15 \\
\hline Rendimiento Medio & 1,78 & 1,44 & 0,98 \\
\hline $\begin{array}{l}\text { Contribución de } \\
\text { Energías Renovables } 2\end{array}$ & 0 & 0 & 0 \\
\hline
\end{tabular}

Indicadores de Eficiencia Energética

\begin{tabular}{|c|c|c|c|c|c|}
\hline & $\begin{array}{l}\text { IEE Demanda } \\
\text { (a) }\end{array}$ & $\begin{array}{l}\text { IEE Sistemas } \\
\text { (b) }\end{array}$ & $\begin{array}{l}\text { IEE } \\
(c)=(a) x(b)\end{array}$ & $\begin{array}{l}\text { Coeficientes } \\
\text { de reparto } \\
\text { (d) }\end{array}$ & \begin{tabular}{|ll} 
Coeficientes \\
de & reparto \\
por & IEE \\
Emisiones \\
$\mathrm{CO}_{2}$ \\
$(\mathrm{c}) \mathrm{x}(\mathrm{d})$ \\
\end{tabular} \\
\hline Calefacción & IEEDC $=4,60$ & IEESC $=1,14$ & IEEC $=5,24$ & 0,3 & 1,57 \\
\hline Refrigeración & IEEDR $=1,21$ & IEESR $=1,26$ & IEER $=1,52$ & 0,58 & 0,88 \\
\hline A,C,S, & IEEDACS $=3,33$ & IEESACS $=1,74$ & IEEACS $=5,81$ & 0,12 & 0,7 \\
\hline
\end{tabular}

CALIFICACIÓN ENERGÉTICA

\begin{tabular}{l|l|l|}
\hline $\begin{array}{l}\text { Indicador } \\
\text { eficiencia de energética } \\
\text { global }\end{array}$ & Valor & $\begin{array}{l}\text { CALIFICACION } \\
\text { ENERGÉTICA }\end{array}$ \\
\hline $\mathrm{EEE}_{\mathrm{G}}$ & 3,15 & $\mathbf{F}$ \\
\hline
\end{tabular}

Fuente: Elaboración propia.

\begin{tabular}{|l|l|}
\hline A & IEEG $<0,29$ \\
\hline B & $0,29<$ IEEG $<$ \\
& 0,55 \\
\hline C & $0,55<$ IEEG $<$ \\
& 0,93 \\
\hline D & $0,93<$ IEEG $<$ \\
& 1,49 \\
\hline E & $1,49<$ IEEG $<$ \\
& 2,96 \\
\hline F & $2,96<$ IEEG $<$ \\
& 3,23 \\
\hline G & $3,23<$ IEEG \\
\hline
\end{tabular}


Tabla 8. Algunos de los parámetros obtenidos en las 19 certificaciones energéticas realizadas a inmuebles con calidades constructivas del 2001

\begin{tabular}{|c|c|c|c|c|c|c|c|c|c|c|c|c|c|c|c|c|}
\hline \multirow{3}{*}{ ID } & \multirow{3}{*}{$\begin{array}{l}\text { Tipo de } \\
\text { Inmueb } \\
\text { le }\end{array}$} & \multirow{3}{*}{\begin{tabular}{|l|}
$\%$ \\
de \\
hue \\
cos
\end{tabular}} & \multirow{3}{*}{\begin{tabular}{|l|} 
Sup \\
de \\
fac \\
had \\
a \\
tota \\
1
\end{tabular}} & \multirow{3}{*}{\begin{tabular}{|l} 
Sup. \\
De \\
suelo \\
con \\
no \\
hab
\end{tabular}} & \multirow{3}{*}{\begin{tabular}{|l|}
$\mathrm{S}$. \\
$\mathrm{de}$ \\
$\mathrm{Cu}$ \\
$\mathrm{bier}$ \\
ta
\end{tabular}} & \multirow{3}{*}{$\begin{array}{l}\text { S.Util } \\
\text { habit } \\
\text { able } \\
\left(\mathrm{m}^{2}\right)\end{array}$} & \multirow{3}{*}{$\begin{array}{l}\begin{array}{l}\text { Siste } \\
\text { ma } \\
\text { ACS }\end{array} \\
\begin{array}{l}\% \text { sol } \\
\text { ar }\end{array}\end{array}$} & \multicolumn{2}{|c|}{\begin{tabular}{|l|} 
Sistema \\
Climatizació \\
n
\end{tabular}} & \multicolumn{7}{|c|}{ Edificio Objeto } \\
\hline & & & & & & & & Frio & Calor & \begin{tabular}{|l|} 
Dem \\
anda \\
de \\
Calef \\
acció \\
n \\
\end{tabular} & $\begin{array}{l}\text { Dem } \\
\text { anda } \\
\text { de } \\
\text { Refri } \\
\text { gerac } \\
\text { ión }\end{array}$ & $\begin{array}{l}\text { Emisi } \\
\text { ones } \\
\mathrm{CO} 2 \\
\text { calef } \\
\text { acció } \\
\mathrm{n}\end{array}$ & $\begin{array}{l}\text { Emisio } \\
\text { nes } \\
\mathrm{CO} 2 \\
\text { refriger } \\
\text { ación }\end{array}$ & $\begin{array}{l}\text { Emisio } \\
\text { nes } \\
\mathrm{CO} 2 \\
\mathrm{ACS}\end{array}$ & $\begin{array}{l}\text { Emisione } \\
\text { TOTALE }\end{array}$ & $\begin{array}{ll}\text { es } & \mathrm{CO} 2 \\
\mathrm{ES} & \end{array}$ \\
\hline & & & & & & & & EER & COP & $\begin{array}{l}\mathrm{kWh} / \\
\mathrm{m}^{2}\end{array}$ & $\begin{array}{l}\mathrm{kWh} / \\
\mathrm{m}^{2}\end{array}$ & \begin{tabular}{|l}
$\mathrm{kgC}$ \\
$\mathrm{O} 2 / \mathrm{m}$ \\
2
\end{tabular} & $\begin{array}{l}\mathrm{kgCO} 2 \\
/ \mathrm{m}^{2}\end{array}$ & $\begin{array}{l}\mathrm{kgCO} 2 \\
/ \mathrm{m}^{2}\end{array}$ & $\begin{array}{l}\mathrm{kgCO} 2 \\
/ \mathrm{m}^{2}\end{array}$ & Calific. \\
\hline 104 & $\begin{array}{l}\text { Piso } \\
\text { pl1 }\end{array}$ & 18 & 60 & 111 & 0 & 111 & $0 \%$ & 3 & 3,15 & 55,63 & 18,84 & 20,28 & 8,47 & 8,15 & 36,9 & $\mathrm{~F}$ \\
\hline 05 & $\begin{array}{l}\text { Piso } \\
\text { pl5 }\end{array}$ & 18 & 60 & 0 & 0 & 111 & $0 \%$ & 3 & 3,15 & 24,01 & 13,64 & 8,75 & 6,14 & 8,15 & 23,04 & $\mathrm{E}$ \\
\hline :06 & $\begin{array}{l}\text { Piso } \\
\text { pl6 }\end{array}$ & 18 & 60 & 0 & 40 & 111 & $0 \%$ & 3 & 3,15 & 44,53 & 22,54 & 16,23 & 10,14 & 8,15 & 34,52 & $\mathrm{~F}$ \\
\hline : & $\begin{array}{l}\text { Piso } \\
\text { atico }\end{array}$ & $\begin{array}{l}17 \\
4\end{array}$ & 92 & 0 & 117 & 117 & $0 \%$ & 3 & 3,15 & 49,72 & 23,09 & 18,13 & 10,39 & 8,15 & 36,67 & $\mathrm{~F}$ \\
\hline 08 & $\begin{array}{l}\text { Piso } \\
\text { pl1 }\end{array}$ & & 61 & 80 & 0 & 80 & $0 \%$ & 3 & 3,15 & 52,56 & 21,15 & 19,16 & 9,52 & 8,15 & 36,83 & $\mathrm{~F}$ \\
\hline 09 & $\begin{array}{l}\text { Piso } \\
\text { pl5 }\end{array}$ & & 61 & 0 & 0 & 80 & $0 \%$ & 3 & 3,15 & 17,38 & 20,55 & 6,34 & 9,25 & 8,15 & 23,74 & $\mathrm{E}$ \\
\hline 10 & $\begin{array}{l}\text { Piso } \\
\text { pl6 }\end{array}$ & & 61 & 0 & 27 & 80 & $0 \%$ & 3 & 3,15 & 36,5 & 27,31 & 13,31 & 12,29 & 8,15 & 33,75 & $\mathrm{E}$ \\
\hline 11 & $\begin{array}{l}\text { Piso } \\
\text { atico }\end{array}$ & & 62 & 0 & 121 & 121 & $0 \%$ & 3 & 3,15 & 44,41 & 21,3 & 16,19 & 9,58 & 8,15 & 33,92 & $\mathrm{E}$ \\
\hline 12 & $\begin{array}{l}\text { Piso } \\
\text { pl1 }\end{array}$ & 18 & 60 & 111 & 0 & 111 & $0 \%$ & 3 & 3,15 & 55,26 & 18,82 & 20,14 & 8,47 & 8,15 & 36,76 & $\mathrm{~F}$ \\
\hline 13 & $\begin{array}{l}\text { Piso } \\
\text { pl5 }\end{array}$ & 18 & 60 & 0 & 0 & 111 & $0 \%$ & 3 & 3,15 & 23,56 & 13,39 & 8,59 & 6,03 & 8,15 & 22,77 & E \\
\hline 14 & $\begin{array}{l}\text { Piso } \\
\text { pl6 }\end{array}$ & 18 & 60 & 0 & 40 & 111 & $0 \%$ & 3 & 3,15 & 44,38 & 22,47 & 16,18 & 10,11 & 8,15 & 34,44 & $\mathrm{~F}$ \\
\hline 15 & $\begin{array}{l}\text { Piso } \\
\text { atico }\end{array}$ & $\begin{array}{l}17 \\
4\end{array}$ & 92 & 0 & 117 & 117 & $0 \%$ & 3 & 3,15 & 49,74 & 23,28 & 18,13 & 10,07 & 8,07 & 36,27 & $\mathrm{~F}$ \\
\hline 16 & $\begin{array}{l}\text { Piso } \\
\text { pl1 }\end{array}$ & & 61 & 78 & 0 & 78 & $0 \%$ & 3 & 3,15 & 45,68 & 22,06 & 16,65 & 9,93 & 8,15 & 34,73 & $\mathrm{~F}$ \\
\hline 17 & $\begin{array}{l}\text { Piso } \\
\text { pl5 }\end{array}$ & & 61 & 0 & 0 & 78 & $0 \%$ & 3 & 3,15 & 12,21 & 23,45 & 4,45 & 10,55 & 8,15 & 23,15 & $\mathrm{E}$ \\
\hline 18 & $\begin{array}{l}\text { Piso } \\
\text { pl6 }\end{array}$ & & 61 & 0 & 26 & 78 & $0 \%$ & 3 & 3,15 & 29,4 & 28,22 & 10,72 & 12,7 & 8,15 & 31,57 & $\mathrm{E}$ \\
\hline 19 & $\begin{array}{l}\text { Piso } \\
\text { atico }\end{array}$ & & 62 & 0 & 110 & 110 & $0 \%$ & 3 & 3,15 & 41,81 & 21,95 & 15,24 & 9,87 & 8,15 & 33,26 & $\mathrm{E}$ \\
\hline í & $\begin{array}{l}\text { Piso } \\
\text { pl1 }\end{array}$ & & 52 & 78 & 0 & 78 & $0 \%$ & 3 & 3,15 & 68,51 & 15,1 & 24,97 & 6,8 & 8,15 & 39,92 & G \\
\hline 21 & $\begin{array}{l}\text { Piso } \\
\text { pl5 }\end{array}$ & & 52 & 0 & 0 & 78 & $0 \%$ & 3 & 3,15 & 29,88 & 12,48 & 10,89 & 5,62 & 8,15 & 24,66 & $\mathrm{E}$ \\
\hline$=22$ & $\begin{array}{l}\text { Piso } \\
\text { pl6 }\end{array}$ & & 52 & 0 & 26 & 78 & $0 \%$ & 3 & 3,15 & 49,43 & 22,05 & 18,02 & 9,92 & 8,15 & 36,09 & $\mathrm{~F}$ \\
\hline
\end{tabular}

Fuente: Elaboración propia. 
Tabla 9. Algunos de los parámetros obtenidos en las 19 certificaciones energéticas realizadas a inmuebles con calidades constructivas del 1991.

\begin{tabular}{|c|c|c|c|c|c|c|c|c|c|c|c|c|c|c|c|c|}
\hline \multirow{3}{*}{ ID } & \multirow{3}{*}{\begin{tabular}{|l|} 
Tipo de \\
Inmueb \\
le
\end{tabular}} & \multirow{3}{*}{$\begin{array}{l}\% \\
\text { de } \\
\text { hue } \\
\text { cos }\end{array}$} & \multirow{3}{*}{$\begin{array}{l}\text { Sup } \\
\text { de } \\
\text { fac } \\
\text { had } \\
\text { a } \\
\text { tota } \\
1\end{array}$} & \multirow{3}{*}{$\begin{array}{l}\text { Sup. } \\
\text { De } \\
\text { suelo } \\
\text { con } \\
\text { no } \\
\text { hab }\end{array}$} & \multirow{3}{*}{\begin{tabular}{|l|}
$\mathrm{S}$. \\
$\mathrm{de}$ \\
$\mathrm{Cu}$ \\
$\mathrm{bier}$ \\
ta
\end{tabular}} & \multirow{3}{*}{$\begin{array}{l}\text { S.Util } \\
\text { habit } \\
\text { able } \\
\left(\mathrm{m}^{2}\right)\end{array}$} & \multirow{3}{*}{$\begin{array}{l}\text { Siste } \\
\text { ma } \\
\text { ACS } \\
\\
\text { \%sol } \\
\text { ar }\end{array}$} & \multicolumn{2}{|c|}{$\begin{array}{l}\text { Sistema } \\
\text { Climatizació } \\
\mathrm{n}\end{array}$} & \multicolumn{7}{|c|}{ Edificio Objeto } \\
\hline & & & & & & & & Frio & Calor & \begin{tabular}{|l} 
Dem \\
anda \\
de \\
Calef \\
acció \\
$\mathrm{n}$ \\
\end{tabular} & 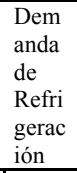 & $\begin{array}{l}\text { Emisi } \\
\text { ones } \\
\mathrm{CO} 2 \\
\text { calef } \\
\text { acció } \\
\mathrm{n} \\
\end{array}$ & $\begin{array}{l}\text { Emisio } \\
\text { nes } \\
\mathrm{CO} 2 \\
\text { refriger } \\
\text { ación }\end{array}$ & $\begin{array}{l}\text { Emisio } \\
\text { nes } \\
\mathrm{CO} 2 \\
\mathrm{ACS}\end{array}$ & \multicolumn{2}{|c|}{$\begin{array}{l}\text { Emisiones } \mathrm{CO} 2 \\
\text { TOTALES }\end{array}$} \\
\hline & & & & & & & & EER & $\mathrm{COP}$ & $\begin{array}{l}\mathrm{kWh} / \\
\mathrm{m}^{2}\end{array}$ & $\begin{array}{l}\mathrm{kWh} / \\
\mathrm{m}^{2}\end{array}$ & \begin{tabular}{|l}
$\mathrm{kgC}$ \\
$\mathrm{O} 2 / \mathrm{m}$ \\
2
\end{tabular} & $\begin{array}{l}\mathrm{kgCO} 2 \\
/ \mathrm{m}^{2}\end{array}$ & $\begin{array}{l}\mathrm{kgCO} 2 \\
/ \mathrm{m}^{2}\end{array}$ & $\begin{array}{l}\mathrm{kgCO} 2 \\
/ \mathrm{m}^{2}\end{array}$ & Calific. \\
\hline 42 & $\begin{array}{l}\text { Piso } \\
\text { pl1 }\end{array}$ & 18 & 60 & 111 & 0 & 111 & $0 \%$ & & & 67,79 & 20,08 & 22,73 & 6,62 & 8,24 & 37,59 & G \\
\hline 43 & $\begin{array}{l}\text { Piso } \\
\text { pl5 }\end{array}$ & 18 & 60 & 0 & 0 & 111 & $0 \%$ & & & 35,79 & 16,32 & 12,00 & 5,38 & 8,24 & 25,62 & $\mathrm{E}$ \\
\hline :44 & $\begin{array}{l}\text { Piso } \\
\text { pl6 }\end{array}$ & 18 & 60 & 0 & 40 & 111 & $0 \%$ & & & 53,63 & 25,25 & 17,98 & 8,33 & 8,24 & 34,55 & $\mathrm{~F}$ \\
\hline 45 & $\begin{array}{l}\text { Piso } \\
\text { atico }\end{array}$ & $\begin{array}{l}17 \\
4\end{array}$ & 92 & 0 & 117 & 117 & $0 \%$ & & & 61,98 & 26,74 & 20,78 & 8,82 & 8,24 & 37,84 & G \\
\hline 46 & $\begin{array}{l}\text { Piso } \\
\text { pl1 }\end{array}$ & & 61 & 80 & 0 & 80 & $0 \%$ & & & 67,58 & 22,58 & 22,66 & 7,45 & 8,24 & 38,35 & G \\
\hline 47 & $\begin{array}{l}\text { Piso } \\
\text { pl5 }\end{array}$ & & 61 & 0 & 0 & 80 & $0 \%$ & & & 27,65 & 22,02 & 9,27 & 7,26 & 8,24 & 24,77 & $\mathrm{E}$ \\
\hline 48 & $\begin{array}{l}\text { Piso } \\
\text { pl6 }\end{array}$ & & 61 & 0 & 27 & 80 & $0 \%$ & & & 47,6 & 30,29 & 15,96 & 9,99 & 8,24 & 34,19 & $\mathrm{E}$ \\
\hline 49 & $\begin{array}{l}\text { Piso } \\
\text { atico }\end{array}$ & & 62 & 0 & 121 & 121 & $0 \%$ & & & 54,08 & 24,71 & 18,14 & 8,15 & 8,24 & 34,53 & $\mathrm{~F}$ \\
\hline 50 & $\begin{array}{l}\text { Piso } \\
\text { pl1 }\end{array}$ & 18 & 60 & 111 & 0 & 111 & $0 \%$ & & & 68,49 & 20,19 & 22,97 & 6,66 & 8,24 & 37,87 & G \\
\hline 51 & $\begin{array}{l}\text { Piso } \\
\text { pl5 }\end{array}$ & 18 & 60 & 0 & 0 & 111 & $0 \%$ & & & 29,89 & 16,05 & 10,02 & 5,3 & 8,24 & 23,56 & E \\
\hline 52 & $\begin{array}{l}\text { Piso } \\
\text { pl6 }\end{array}$ & 18 & 60 & 0 & 40 & 111 & $0 \%$ & & & 54,39 & 25,51 & 18,24 & 8,42 & 8,24 & 34,9 & $\mathrm{~F}$ \\
\hline 53 & $\begin{array}{l}\text { Piso } \\
\text { atico }\end{array}$ & $\begin{array}{l}17 \\
4\end{array}$ & 92 & 0 & 117 & 117 & $0 \%$ & & & 62,08 & 26,99 & 20,82 & 8,91 & 8,24 & 37,97 & G \\
\hline :54 & $\begin{array}{l}\text { Piso } \\
\text { pl1 }\end{array}$ & & 61 & 78 & 0 & 78 & $0 \%$ & & & 60,15 & 23,75 & 20,17 & 7,84 & 8,24 & 36,25 & $\mathrm{~F}$ \\
\hline 55 & $\begin{array}{l}\text { Piso } \\
\text { pl5 }\end{array}$ & & 61 & 0 & 0 & 78 & $0 \%$ & & & 21,28 & 24,65 & 7,13 & 8,13 & 8,24 & 23,5 & E \\
\hline 56 & $\begin{array}{l}\text { Piso } \\
\text { pl6 }\end{array}$ & & 61 & 0 & 26 & 78 & $0 \%$ & & & 40,74 & 31,44 & 13,66 & 10,37 & 8,24 & 32,27 & E \\
\hline 57 & $\begin{array}{l}\text { Piso } \\
\text { atico }\end{array}$ & & 62 & 0 & 110 & 110 & $0 \%$ & & & 50,95 & 25,45 & 17,09 & 8,4 & 8,24 & 33,73 & $\mathrm{E}$ \\
\hline 58 & $\begin{array}{l}\text { Piso } \\
\text { pl1 }\end{array}$ & & 52 & 78 & 0 & 78 & $0 \%$ & & & 86,56 & 16,27 & 29,03 & 5,37 & 8,24 & 42,64 & G \\
\hline 59 & $\begin{array}{l}\text { Piso } \\
\text { pl5 }\end{array}$ & & 52 & 0 & 0 & 78 & $0 \%$ & & & 44,38 & 13,43 & 14,88 & 4,43 & 8,24 & 27,55 & $\mathrm{E}$ \\
\hline$=60$ & $\begin{array}{l}\text { Piso } \\
\text { pl6 }\end{array}$ & & 52 & 0 & 26 & 78 & $0 \%$ & & & 63,03 & 24,76 & 21,14 & 8,17 & 8,24 & 37,55 & G \\
\hline
\end{tabular}

Fuente: Elaboración propia. 
Tabla 10. Algunos de los parámetros obtenidos en las 19 certificaciones energéticas realizadas a inmuebles con calidades constructivas del 2012

\begin{tabular}{|c|c|c|c|c|c|c|c|c|c|c|c|c|c|c|c|c|}
\hline \multirow{3}{*}{ ID } & \multirow{3}{*}{$\begin{array}{l}\text { Tipo de } \\
\text { Inmueb } \\
\text { le }\end{array}$} & \multirow{3}{*}{$\begin{array}{l}\% \\
\text { de } \\
\text { hue } \\
\text { cos }\end{array}$} & \multirow{3}{*}{$\begin{array}{l}\text { Sup } \\
\text { de } \\
\text { fac } \\
\text { had } \\
\text { a } \\
\text { tota } \\
1\end{array}$} & \multirow{3}{*}{$\begin{array}{l}\text { Sup. } \\
\text { De } \\
\text { suelo } \\
\text { con } \\
\text { no } \\
\text { hab }\end{array}$} & \multirow{3}{*}{$\begin{array}{l}\text { S. } \\
\text { de } \\
\text { Cu } \\
\text { bier } \\
\text { ta }\end{array}$} & \multirow{3}{*}{$\begin{array}{l}\text { S.Util } \\
\text { habit } \\
\text { able } \\
\left(\mathrm{m}^{2}\right)\end{array}$} & \multirow{3}{*}{$\begin{array}{l}\text { Siste } \\
\text { ma } \\
\text { ACS }\end{array}$} & \multicolumn{2}{|c|}{$\begin{array}{l}\text { Sistema } \\
\text { Climatizació } \\
\mathrm{n}\end{array}$} & \multicolumn{7}{|c|}{ Edificio O Edificio Objeto bjeto } \\
\hline & & & & & & & & Frio & Calor & \begin{tabular}{|l|} 
Dem \\
anda \\
de \\
Calef \\
acció \\
$\mathrm{n}$ \\
\end{tabular} & $\begin{array}{l}\text { Dem } \\
\text { anda } \\
\text { de } \\
\text { Refri } \\
\text { gerac } \\
\text { ión } \\
\end{array}$ & $\begin{array}{l}\text { Emisi } \\
\text { ones } \\
\mathrm{CO} 2 \\
\text { calef } \\
\text { acció } \\
\mathrm{n} \\
\end{array}$ & $\begin{array}{l}\text { Emisio } \\
\text { nes } \\
\mathrm{CO} 2 \\
\text { refriger } \\
\text { ación }\end{array}$ & $\begin{array}{l}\text { Emisio } \\
\text { nes } \\
\mathrm{CO} 2 \\
\mathrm{ACS}\end{array}$ & \multicolumn{2}{|c|}{$\begin{array}{l}\text { Emisiones } \mathrm{CO} 2 \\
\text { TOTALES }\end{array}$} \\
\hline & & & & & & & & EER & $\mathrm{COP}$ & $\begin{array}{l}\mathrm{kWh} / \\
\mathrm{m}^{2}\end{array}$ & $\begin{array}{l}\mathrm{kWh} / \\
\mathrm{m}^{2}\end{array}$ & \begin{tabular}{|l}
$\mathrm{kgC}$ \\
$\mathrm{O} 2 / \mathrm{m}$ \\
2
\end{tabular} & $\begin{array}{l}\mathrm{kgCO} 2 \\
/ \mathrm{m}^{2}\end{array}$ & $\begin{array}{l}\mathrm{kgCO} 2 \\
/ \mathrm{m}^{2}\end{array}$ & $\begin{array}{l}\mathrm{kgCO} 2 \\
/ \mathrm{m}^{2}\end{array}$ & Calific. \\
\hline 23 & $\begin{array}{l}\text { Piso } \\
\text { pl1 }\end{array}$ & 18 & 60 & 111 & 0 & 111 & $70 \%$ & 3,21 & 3,61 & 28,94 & 18,88 & 7,48 & 7,94 & 0,82 & 16,24 & $\mathrm{D}$ \\
\hline 24 & $\begin{array}{l}\text { Piso } \\
\text { p15 }\end{array}$ & 18 & 60 & 0 & 0 & 111 & $70 \%$ & 3,21 & 3,61 & 21,76 & 13,44 & 5,62 & 5,65 & 0,82 & 12,09 & $\mathrm{D}$ \\
\hline 25 & $\begin{array}{l}\text { Piso } \\
\text { pl6 }\end{array}$ & 18 & 60 & 0 & 40 & 111 & $70 \%$ & 3,21 & 3,61 & 35,86 & 19,76 & 9,27 & 8,31 & 0,82 & 18,4 & $\mathrm{E}$ \\
\hline 26 & $\begin{array}{l}\text { Piso } \\
\text { atico }\end{array}$ & $\begin{array}{l}17 \\
4\end{array}$ & 92 & 0 & 117 & 117 & $70 \%$ & 3,21 & 3,61 & 40,5 & 19,75 & 10,47 & 8,3 & 0,82 & 19,59 & $\mathrm{E}$ \\
\hline 27 & $\begin{array}{l}\text { Piso } \\
\text { pl1 }\end{array}$ & & 61 & 80 & 0 & 80 & $70 \%$ & 3,21 & 3,61 & 27,44 & 21,48 & 7,09 & 9,03 & 0,82 & 16,94 & $\mathrm{D}$ \\
\hline 28 & $\begin{array}{l}\text { Piso } \\
\text { pl5 }\end{array}$ & & 61 & 0 & 0 & 80 & $70 \%$ & 3,21 & 3,61 & 14,99 & 20,82 & 3,87 & 8,75 & 0,82 & 13,44 & $\mathrm{D}$ \\
\hline 29 & $\begin{array}{l}\text { Piso } \\
\text { pl6 }\end{array}$ & & 61 & 0 & 27 & 80 & $70 \%$ & 3,21 & 3,61 & 26,41 & 25,21 & 6,82 & 10,6 & 0,82 & 18,24 & $\mathrm{E}$ \\
\hline 30 & $\begin{array}{l}\text { Piso } \\
\text { atico }\end{array}$ & & 62 & 0 & 121 & 121 & $70 \%$ & 3,21 & 3,61 & 34,49 & 17,66 & 8,91 & 7,42 & 0,82 & 17,15 & $\mathrm{D}$ \\
\hline 31 & $\begin{array}{l}\text { Piso } \\
\text { pl1 }\end{array}$ & 18 & 60 & 111 & 0 & 111 & $70 \%$ & 3,21 & 3,61 & 30,78 & 18,47 & 7,96 & 7,77 & 0,82 & 16,55 & $\mathrm{D}$ \\
\hline 32 & $\begin{array}{l}\text { Piso } \\
\text { pl5 }\end{array}$ & 18 & 60 & 0 & 0 & 111 & $70 \%$ & 3,21 & 3,61 & 21,65 & 13,39 & 5,59 & 5,63 & 0,82 & 12,04 & $\mathrm{D}$ \\
\hline 33 & $\begin{array}{l}\text { Piso } \\
\text { pl6 }\end{array}$ & 18 & 60 & 0 & 40 & 111 & $70 \%$ & 3,21 & 3,61 & 35,65 & 19,65 & 9,21 & 8,26 & 0,82 & 18,29 & $\mathrm{E}$ \\
\hline 34 & $\begin{array}{l}\text { Piso } \\
\text { atico }\end{array}$ & $\begin{array}{l}17 \\
4\end{array}$ & 92 & 0 & 117 & 117 & $70 \%$ & 3,21 & 3,61 & 40,38 & 20,08 & 10,44 & 8,44 & 0,82 & 19,7 & $\mathrm{E}$ \\
\hline 35 & $\begin{array}{l}\text { Piso } \\
\text { pl1 }\end{array}$ & & 61 & 78 & 0 & 78 & $70 \%$ & 3,21 & 3,61 & 21,36 & 22,47 & 5,52 & 9,45 & 0,82 & 15,79 & $\mathrm{D}$ \\
\hline 36 & $\begin{array}{l}\text { Piso } \\
\text { pl5 }\end{array}$ & & 61 & 0 & 0 & 78 & $70 \%$ & 3,21 & 3,61 & 10,16 & 23,92 & 2,62 & 10,06 & 0,82 & 13,5 & $\mathrm{D}$ \\
\hline 37 & $\begin{array}{l}\text { Piso } \\
\text { pl6 }\end{array}$ & & 61 & 0 & 26 & 78 & $70 \%$ & 3,21 & 3,61 & 21,12 & 27,63 & 5,46 & 11,62 & 0,82 & 17,9 & $\mathrm{E}$ \\
\hline 38 & $\begin{array}{l}\text { Piso } \\
\text { atico }\end{array}$ & & 62 & 0 & 110 & 110 & $70 \%$ & 3,21 & 3,61 & 30,37 & 18,36 & 7,85 & 7,72 & 0,82 & 16,39 & $\mathrm{D}$ \\
\hline 39 & $\begin{array}{l}\text { Piso } \\
\text { pl1 }\end{array}$ & & 52 & 78 & 0 & 78 & $70 \%$ & 3,21 & 3,61 & 44,62 & 13,7 & 11,53 & 5,76 & 0,82 & 18,11 & $\mathrm{E}$ \\
\hline 40 & $\begin{array}{l}\text { Piso } \\
\text { pl5 }\end{array}$ & & 52 & 0 & 0 & 78 & $70 \%$ & 3,21 & 3,61 & 27,3 & 12,52 & 7,05 & 5,26 & 0,82 & 13,13 & $\mathrm{D}$ \\
\hline$=41$ & $\begin{array}{l}\text { Piso } \\
\mathrm{pl} 6\end{array}$ & & 52 & 0 & 26 & 78 & $70 \%$ & 3,21 & 3,61 & 40,93 & 18,74 & 10,58 & 7,88 & 0,82 & 19,28 & $\mathrm{E}$ \\
\hline
\end{tabular}

Fuente: Elaboración propia.

En viviendas con calidades constructivas del 2012 predominan las certificaciones con letra $\mathrm{D}$, con excepción de casos aislados que por orientaciones y por superficies de cubierta baja a la E. De acuerdo con el CTE, todas las viviendas posteriores a su puesta en vigor deberían tener una calificación $\mathrm{D}$, siendo la calificación $\mathrm{E}$ de algunas 
de ellas producto del sistema de valoración del programa Ce3, que trabaja a favor de la seguridad (tiende a dar la menor calificación cuando los valores son cercanos a los límites). Por tanto, al utilizar coeficientes de transmisión límites de la normativa, internamente calcula un $\mathrm{IEE}_{\mathrm{G}}$ que está al límite de la calificación $\mathrm{E}$, pero muy cercano a la calificación D (Tabla 10).

El análisis descriptivo de los indicadores energéticos calculados confirman la reducción de las demandas energéticas de calefacción en aproximadamente la mitad entre 1990 y 2012 (Tabla 11). Fenómeno que se observa también en las emisiones de $\mathrm{CO}_{2}$ totales y en el consumo total de energía primaria. Se pueden observar también una reducción significativa en las emisiones de $\mathrm{CO}_{2}$ por ACS, debido a la introducción de paneles solares para cubrir el 70\% de la demanda, según lo establece el CTE.

Tabla 11. Datos estadísticos de los indicadores energéticos calculados.

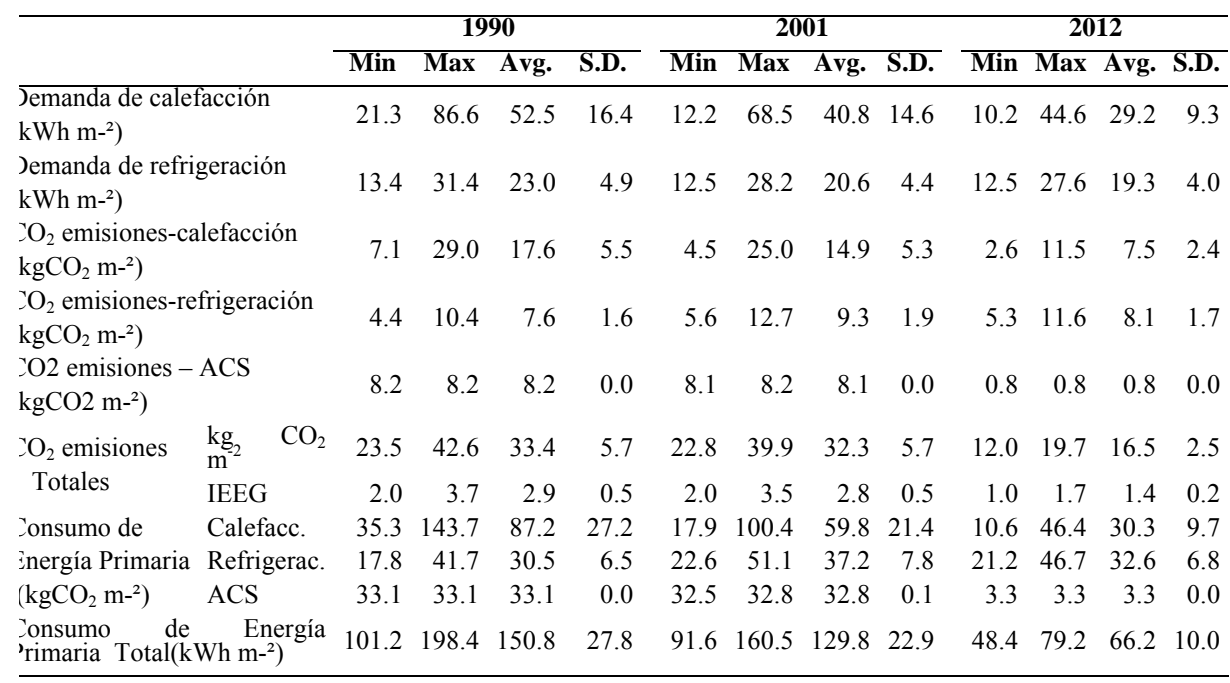

Fuente: Elaboración propia.

En 1990, la energía necesaria para mantener la calidad ambiental interior para calefacción y para ACS eran las principales fuentes de consumo primario de energía. Estas necesidades se han reducido gracias a las mejoras de la eficiencia energética de los métodos constructivos. En 2012, el consumo de energía para calefacción fue la tercera parte de la energía que se requería en 1990, y una décima parte la energía para ACS. El cambio más significativo en los métodos de construcción, que ha permitido esta reducción, es la introducción de un porcentaje mínimo de ACS mediante Energía Solar.

Es importante precisar que los programas informáticos utilizados para el cálculo de la eficiencia energética proyectan unas necesidades de calefacción que no son aportadas por ningún equipo en la zona de estudio (zona climática A4), bien por que los edificios no dispongan de ellas o porque no hay costumbre de utilizarlas. Para 
alcanzar una aceptable sensación térmica dentro de las viviendas, generalmente las personas tienden a abrigarse más o a poner una pequeña estufa en algún punto del inmueble, como puede ser en el baño o bajo la mesa del salón, antes que utilizar un sistema de calefacción para toda la vivienda. Esta situación la normativa no lo contempla, ya que generaliza los hábitos de calefacción y/o refrigeración al momento de realizar los cálculos.

Por otro lado, el consumo primario de energía para refrigeración se ha mantenido constante en términos globales durante el periodo 1990-2012, ya que las mayores necesidades de energía de los áticos se compensan con los menores requerimientos de las plantas bajas.

Por planta y año, se observó que en todas las plantas han disminuido significativamente las emisiones de $\mathrm{CO}_{2}$ por ACS y calefacción. Esta reducción es producto de la introducción de las mejoras en los aislamientos. Por el contrario, las emisiones de $\mathrm{CO}_{2}$ por refrigeración se han mantenido en todas las plantas, con excepción del ático, donde se han reducido ligeramente.

En la Tabla 12 se observan las correlaciones de los principales factores que miden la eficiencia en función de los años, con las superficies de suelos en contacto con local no calefactado y cubiertas. Se excluyeron las superficies de fachadas totales debido a que son similares en la promoción. Se observó al considerar los métodos constructivos de 1990 y 2001, que existe una correlación muy significativa entre la demanda, la emisión de $\mathrm{CO}_{2}$ y el consumo de energía primaria en calefacción con la superficie de suelo no calefactado, que no se refleja si se consideran los métodos constructivos de 2012. Estas correlaciones indican que hasta la entrada en vigor del CTE se descuidaba el aislamiento mínimo en las construcciones con locales no calefactados, produciendo que la temperatura en las plantas bajas fuera inferior a las del resto de plantas, aumentando las necesidades de calefacción con el consiguiente aumento del consumo de energía (menor eficiencia energética) y del gasto para los propietarios.

Por el contrario, en función de los métodos constructivos de 2012, la superficie de cubierta es el elemento más determinante por la correlación existente con la demanda y emisiones de $\mathrm{CO}_{2}$ de calefacción (aumento de las necesidades de calefacción).

Destaca también, el cambio de tendencia entre los años 1990 y 2001 tanto en la demanda como en las emisiones de $\mathrm{CO}_{2}$ producto del sistema de refrigeración. En 1990 existía una correlación significativa con la superficie de cubierta, la que deja de ser significativa en el 2001, debido a una pequeña mejora en la ejecución de las cubiertas.

\section{OPORTUNIDADES $Y$ PROBLEMAS DE LA EFICIENCIA ENERGÉTICA EN ESPAÑA}

El 40\% del consumo total de energía de la UE se debe al sector de la edificación. Este sector que está en continua expansión, hace que se produzca un aumento en el consumo. Por tanto, se necesitan dos medidas importantes en el sector de la construcción para reducir la dependencia energética y las emisiones de gases de efecto inver- 
nadero de la Unión Europea: la reducción del consumo de energía y el uso de fuentes de energía renovables [23].

La plena aplicación de las medidas existentes en Europa producirían: una industria europea más competitiva; la reducción de la dependencia energética, contribuiría al crecimiento económico y a la creación de empleo; contribuiría a la reducción de las emisiones de gases de efecto invernadero y de los efectos perjudiciales en el medio ambiente acarreados por la generación de energía; el ahorro de hasta $1000 €$ por familia al año, y la mejora de las condiciones de vida y el bienestar de sus ciudadanos.

Tabla 12. Correlaciones entre los indicadores energéticos.

\begin{tabular}{|c|c|c|c|c|c|c|}
\hline & \multicolumn{2}{|c|}{1990} & \multicolumn{2}{|c|}{2001} & \multicolumn{2}{|c|}{2012} \\
\hline & $\begin{array}{c}\text { Planta en } \\
\text { contacto } \\
\text { con } \\
\text { espacio no } \\
\text { calefactado }\end{array}$ & $\begin{array}{c}\text { Planta } \\
\text { de } \\
\text { Cubierta }\end{array}$ & $\begin{array}{c}\text { Planta en } \\
\text { contacto } \\
\text { con } \\
\text { espacio no } \\
\text { calefactado }\end{array}$ & $\begin{array}{c}\text { Planta } \\
\text { de } \\
\text { Cubierta }\end{array}$ & $\begin{array}{c}\text { Planta en } \\
\text { contacto } \\
\text { con } \\
\text { espacio no } \\
\text { calefactado }\end{array}$ & $\begin{array}{c}\text { Planta } \\
\text { de } \\
\text { Cubierta }\end{array}$ \\
\hline $\begin{array}{l}\text { Demanda de } \\
\text { calefacción }\end{array}$ & $0.634 * *$ & 0.159 & $0.607 * *$ & 0.226 & 0.084 & $0.506^{*}$ \\
\hline $\begin{array}{l}\text { Demanda de } \\
\text { refrigeración }\end{array}$ & -0.303 & $0.502 *$ & -0.202 & 0.383 & -0.044 & 0.077 \\
\hline $\begin{array}{l}\mathrm{CO}_{2} \\
\text { emisiones- } \\
\text { calefacción }\end{array}$ & $0.634 * *$ & 0.16 & $0.607 * *$ & 0.226 & 0.085 & $0.506^{*}$ \\
\hline $\begin{array}{l}\mathrm{CO}_{2} \\
\text { emisiones- } \\
\text { refrigeración }\end{array}$ & -0.303 & $0.503^{*}$ & -0.197 & 0.364 & -0.043 & 0.076 \\
\hline $\begin{array}{l}\mathrm{CO}_{2} \\
\text { emisiones- } \\
\text { Totales }\end{array}$ & $0.527 *$ & 0.296 & $0.501 *$ & 0.335 & 0.052 & $0.541 *$ \\
\hline IEEG & $0.529 *$ & 0.296 & $0.507^{*}$ & 0.329 & 0.048 & $0.552 *$ \\
\hline $\begin{array}{l}\text { Consumo de } \\
\text { energía } \\
\text { primaria de } \\
\text { calefacción }\end{array}$ & $0.634 * *$ & 0.159 & $0.607 * *$ & 0.226 & 0.084 & $0.506^{*}$ \\
\hline $\begin{array}{l}\text { Consumo de } \\
\text { energía } \\
\text { primaria de } \\
\text { refrigeración }\end{array}$ & -0.303 & $0.502 *$ & -0.197 & 0.365 & -0.044 & 0.077 \\
\hline $\begin{array}{l}\text { Consumo de } \\
\text { energía } \\
\text { primaria } \\
\text { Total }\end{array}$ & $0.550 *$ & 0.273 & $0.501 *$ & 0.335 & 0.052 & $0.541 *$ \\
\hline
\end{tabular}

Fuente: Elaboración propia. 
Geller y Nadel [24] consideran que las políticas y programas de eficiencia energética funcionan mejor si están integrados en las estrategias de transformación del mercado. En este sentido, la UE debería de trabajar en la gestión de la demanda energética como una importante herramienta para influir en el mercado energético mundial, y por lo tanto, a medio y largo plazo, asegurar el suministro de energía [23].

España tiene la oportunidad de lograr estos objetivos, pero para ello debe resolver los siguientes problemas: Cumplir los plazos de la legislación existente, promover la conciencia ciudadana, disminuir el amplio stock en venta de viviendas construidas de manera poco eficiente (viviendas construidas antes del 2007) sustituyéndolas por nuevos edificios más eficientes, y regular y penalizar a las Comunidades Autónomas que no cumplan.

El Real Decreto 235/2013 [20] hace obligatorio obtener un certificado energético para inmuebles nuevos y existentes en venta o en alquiler. Este certificado da a los compradores o arrendatarios una idea de lo eficiente que es el inmueble, permitiendo ahorrar energía de distintas formas, ya que en los certificados se adjunta un documento donde se asesora a los propietarios de las medidas que pueden acometer para mejorar una o dos letras, si es posible. La inspección de estos certificados energéticos debe de ser realizados por las Comunidades Autónomas de forma muy distinta a la que se realizaba en edificios de nueva construcción, que era casi inexistente.

Los edificios tienen un impacto en el consumo energético a largo plazo. Dado el largo ciclo de renovación para los edificios. Por ello, los edificios existentes que sean objeto de reformas importantes deben cumplir con los requisitos mínimos de eficiencia energética adaptados a las condiciones climáticas de la zona [25]. Haciendo especial hincapié en el dimensionamiento de los sistemas de calefacción y refrigeración, adaptándolos a la realidad del edificio.

Las Comunidades Autónomas tienen la autoridad para inspeccionar, controlar y renovar los certificados energéticos. Sin su participación, sería imposible alcanzar los objetivos establecidos por las regulaciones gubernamentales.

La legislación sobre certificados energéticos sin un adecuado seguimiento, conduce a la falta de cumplimiento. Las medidas que se pueden tomar para aumentar su eficacia son [25]: Imponer sanciones para aumentar el cumplimiento de la normativa; hacer público el acceso a la base de datos de certificados, el control sobre el terreno de los certificados, que aumentaría la calidad del certificado y de los técnicos independientes, favorecer el acceso de los particulares a subvenciones y microcréditos, a través de la educación y publicidad fomentar una conciencia ciudadana que haría que los inmuebles incrementen su valor en relación a su calificación, y aumentar los impuestos sobre los inmuebles menos eficientes. Herring [26] sugiere que la manera más eficaz de reducir el consumo de energía es mediante impuestos, a pesar de que esto implica un costo económico para la sociedad.

Se necesitan medidas que aumenten el número de edificios que no sólo cumplan los requisitos mínimos de efíciencia energética actuales, sino que también sean más eficientes energéticamente, lo que reduciría el consumo de energía y las emisiones de dióxido de carbono [23]. 
El Certificado Energético es una buena herramienta, necesaria para conocer el estado real de los edificios existentes y que ayuda a hacerlos más eficientes. Por ejemplo, en el certificado de una vivienda calificada con $\mathrm{G}$, debe de reflejar algunas medidas para mejorar su rendimiento energético y el propietario debe decidir si llevarlas a cabo o no. Estas medidas deben tener en cuenta, además de sus características térmicas, otros factores que desempeñan un papel cada vez más importante, tales como instalaciones de calefacción y aire acondicionado, el uso de los recursos renovables de energía, calefacción pasiva y elementos de refrigeración, el sombreado, la calidad del aire en interiores, luz natural suficiente, y el diseño del edificio. La metodología de cálculo de la eficiencia energética debe tener en cuenta la zona climática del inmueble y tener en cuenta las normas europeas actuales.

Para motivar que el propietario acometa estas medidas de mejora, se podrían incluir subsidios directos, programas de préstamos bonificados o préstamos a bajo interés, subvenciones o sistemas de garantía de préstamos. Las autoridades y otras instituciones que presten este tipo de medidas financieras podrían vincular su aplicación a la certificación de eficiencia energética [23].

Uno de los principales problemas de España es la gran cantidad de viviendas en venta construido bajo la antigua legislación (antes del CTE). El desarrollo del área urbanizada en 2005 multiplicó casi 2.5 veces en comparación con 1990. En este período, la mayoría de esta área estaba cubierta por uso residencial. Por ejemplo, en 2005 representaba el $98.3 \%$, frente a los edificios del sector terciario. Esta expansión excesiva llevó a una construcción de baja calidad y por consiguiente de baja eficiencia energética.

El consumo final de energía en uso residencial muestra que el aire acondicionado, dada su estacionalidad, no tiene un impacto significativo en el consumo, a pesar de que contribuye a la generación de picos en la demanda de electricidad, lo que contribuye a los problemas de suministro de electricidad locales en verano, cuando las temperaturas exteriores son mucho más altas [27]. Cabe destacar que las instalaciones térmicas (calefacción y agua caliente) representan dos tercios del consumo de energía residencial.

La comparación del consumo de energía de calefacción de una vivienda media española con una en el resto de Europa también es interesante. Este consumo supone en España un $41.7 \%$ del consumo total de una vivienda tipo en comparación con $67.9 \%$ para Europa [27]. Hay que tener en cuenta que el porcentaje de superficie construida que ocupa la vivienda es más alto que cualquier otro uso, y sólo dos de cada tres casas están destinados a residencia habitual [27]. Por lo tanto, se puede concluir que el crecimiento en el consumo de energía no es proporcional al crecimiento en área construida, por lo que esta variable no se puede utilizar como la única figura en la predicción del consumo en este sector. Si la intensidad energética en el sector residencial español se compara con otros países de la UE, se observa que la expresada en tep/vivienda, el sector residencial en España es aproximadamente el $60 \%$ de la media europea [27], que se corresponde estrechamente con las cifras de otros países mediterráneos, como Grecia o Italia. 
Las administraciones públicas españolas disponen de un gran número de inmuebles en propiedad y arrendadas, pero la falta de dinero provocada por la crisis económica actual hace que estas no den ejemplo, incumpliendo la legislación vigente [15]. El sector público debe liderar el camino en el campo de la eficiencia energética de los edificios, y por lo tanto, los planes nacionales deben fijar objetivos más ambiciosos para los edificios ocupados por las autoridades públicas.

\section{CONCLUSIONES}

En los últimos 25 años solo ha existido un gran cambio en los materiales empleados para la construcción de edificios, motivado por la aprobación del CTE. Esta normativa entró en vigor el 17 de marzo del 2006 para nuevos proyectos, y por tanto, los primeros inmuebles que incorporaron los nuevos materiales y sistemas energéticamente más eficientes fueron construidos a partir de 2007.

La eficiencia energética de los edificios en España está mejorando más lentamente que en otros países europeos. El actual Real Decreto 235/2013 podría ofrecer una nueva oportunidad para recuperar el tiempo perdido. Sin embargo, esto dependerá de la participación de las Comunidades Autónomas y de sensibilización de la población. Los avances en la eficiencia energética están en manos del gobierno español. Acciones más concretas deben de ser tomadas con el fin de aprovechar el gran potencial de ahorro energético en los edificios y reducir las grandes diferencias con otros estados miembros en este sector. Sin embargo, la solución es difícil debido a la crisis económica, la desmotivación de los ciudadanos sobre el tema, la descentralización de las competencias en materia de energía, y el gran stock de viviendas sin vender basadas en legislaciones menos eficientes que hace que no se construyan nuevas viviendas.

En la zona A4, los cambios en los métodos constructivos han producido una disminución de aproximadamente el $50 \%$ en el consumo de energía primaria y de emisiones de $\mathrm{CO}_{2}$ globales. Esto indica que aunque la inversión económica inicial sea mayor, por el uso de materiales y sistemas energéticamente más eficientes, el consumo de energía (electricidad y gas) durante su vida útil es mucho menor, produciendo un ahorro económico y haciendo que el edificio sea más sostenible energéticamente.

Para mejorar considerablemente la eficiencia energética real de las viviendas de la zona climática $\mathrm{A} 4$, y reducir la incertidumbre en los resultados de los programas informáticos utilizados en España para el cálculo de la eficiencia energética, se debería realizar un estudio pormenorizado de las facturas eléctricas, de agua y de gas, además del de los elementos constructivos y sistemas empleados, para ser incorporados en los cálculos de los programas.

Los resultados presentados en este trabajo son preliminares, y servirán de base para posteriores estudios relacionados con el cálculo de los costes económicos de los mejoras en los métodos de construcción, de las medidas a considerar para la mejora de la calificación energética en al menos una o dos letras en las edificaciones de la zona de estudio, el cálculo de los periodos de amortización de la implementación de estas medidas, entre otros. 


\section{BIBLIOGRAFÍA}

[1] European Union. Green paper on an energy strategy for sustainable, competitive and secure energy. $\mathrm{COM}(2006) 105$ Final; Brussels; 2006.

[2]Streimikiene D, Šivickas G. The EU sustainable energy policy indicators framework. Environ Int 2008;34:1227-1240.

[3] European Union. Energy efficiency: delivering the 20\% target. COM(2008) 772 final; Brussels, 13.11.2008.

[4] European Communities. An Energy Policy for Europe; $\operatorname{COM(2007)~} 1$ final; Brussels; 2007.

[5] Council of the European Union. Brussels European Council 2007, Presidency conclusions, (7224/1/07); Brussels; 2007.

[6] European Communities. Panorama of energy. Energy statistics to support EU policies and solutions; Luxembourg: Eurostat, Statistical books. Office for Official Publications of the European Communities; 2009.

[7] Omer AM. Energy, environment and sustainable development. Renew Sustain Energ Rev 2008;12:2265-2300.

[8] European Commission. Background Information Paper for the Public Consultation on the Evaluation and Revision of the Action Plan for Energy Efficiency; COM (2006) 545; Brussels; 2006.

[9] European Communities. Efficiency Plan 2011; COM(2011) 109 final; Brussels; 2011.

[10] European Commission. Background Information Paper for the Public Consultation on the Evaluation and Revision of the Action Plan for Energy Efficiency; COM (2006) 545; Brussels; 2006.

[11] Mendiluce M, Pérez-Arriaga I, Ocaña C. Comparison of the evolution of energy intensity in Spain and in the EU-15. Why is Spain different? Energ Pol 2010;38: 639-645.

[12] Plataforma Tecnológica Española de Eficiencia Energética. Documento de visión de la Eficiencia Energética en España; Madrid; 2009.

[13] Eurostat. Energy, transport and environment indicators 2010 edition. Luxembourg: Publications Office of the EU; 2011.

[14] European Communities. Directive 2010/31/EU of the European Parliament and of the Council of 19 May 2010 on the energy performance of buildings (recast); 2010.

[15] Código Técnico de la Edificación; RD 314/2006. Madrid; 2006.

[16] Alcántara V, Duro JA. Inequality of energy intensities across OECD countries: a note. Energ Pol 2004;32:1257-1260.

[17] Real Decreto 47/2007, de 19 de enero, por el que se aprueba el Procedimiento básico para la certificación de eficiencia energética de edificios de nueva construcción; Madrid; 2007.

[18] Real Decreto 1027/2007, de 20 de julio, por el que se aprueba el Reglamento de Instalaciones Térmicas en los Edificios. Madrid; 2007. 
[19] Real Decreto 238/2013, de 5 de abril, por el que se modifican determinados artículos e instrucciones técnicas del Reglamento de Instalaciones Térmicas en los Edificios, aprobado por Real Decreto 1027/2007, de 20 de julio. Madrid; 2013.

[20] Real Decreto 235/2013, de 5 de abril, por el que se aprueba el procedimiento básico para la certificación de la eficiencia energética de los edificios. Madrid; 2013.

[21] Odysee. Energy Efficiency Indicators in Europe; Available at: http://www.odyssee-indicators.org/

[22] Odysee. Energy Efficiency Profile: Spain; Odysee, October 2012.

[23] European Communities. Directive 2010/31/EU of the European Parliament and of the Council of 19 May 2010 on the energy performance of buildings (recast); 2010.

[24] Geller H, Nadel S. Market transformation strategies to promote end-use efficiency. Annu Rev Energ Environ 1994;19:301-346.

[25] European Union. Implementing the Energy Performance of Buildings Directive (EPDB). Featuring country reports 2010; 2011.

[26] Herring H. Does energy efficiency save energy? The debate and its consequences. Appl Energ 1999;63:209-226.

[27] Instituto para la diversificación y ahorro de la energía, Ministerio de Industria, Turismo y Comercio. Saving and Energy Efficiency Strategy in Spain 2004-2012, Action plan 2008 - 2012; Madrid; 2007. 